\title{
LA RECONSIDERACIÓN ANTE EL CIADI: UN MECANISMO PROCESAL PARA FOMENTAR LA CORRECCIÓN DEL LAUDO
}

\section{RECONSIDERATION IN ICSID ARBITRATION: A PROCEDURAL MECHANISM PROMOTING THE CORRECTNESS OF AWARDS}

\author{
Laura Aragonés Molina \\ Profesora Visitante de Derecho internacional público y relaciones internacionales \\ Universidad de Alcalá
}

Recibido: 12.06.2020 / Aceptado:01.07.2020

DOI: https://doi.org/https://doi.org/10.20318/cdt.2020.5603

\begin{abstract}
Resumen: En los últimos años varios tribunales arbitrales del CIADI se han pronunciado sobre una posible facultad de reconsideración de las decisiones preliminares dictadas en los procedimientos que se bifurcan o trifurcan (jurisdicción, fondo y determinación de la indemnización). La práctica arbitral más reciente, apartándose de la línea marcada en los primeros casos, se ha inclinado por reconocer esta facultad. Las diferentes interpretaciones que han realizado estos tribunales sobre el principio de cosa juzgada y sobre los poderes inherentes que puede poseer un órgano arbitral inducen a reflexionar sobre dos cuestiones principales; primera, las implicaciones que tiene la consolidación de una facultad de reconsideración para el actual sistema de recursos previstos en la normativa CIADI; y, segunda, con carácter más general, sobre los problemas de coherencia en el seno del sistema CIADI y las relaciones entre este y el DI general.
\end{abstract} CIADI.

Palabras clave: coherencia, poderes inherentes, reconsideración, principios generales del derecho,

\begin{abstract}
In the last years several arbitral tribunals constituted according to the ICSID Convention and Rules have ruled on a potential power to reconsider preliminary decisions issued in bifurcated or trifurcated proceedings (jurisdiction, merits and quantum). The most recent arbitral practice has favored the recognition of this power changing the legal position previously maintained. The different interpretations made by these arbitral tribunals on the res judicata principle and their inherent powers allow us to reflect on two main questions; on the one side, the implications of the consolidation of such a power for the current system of remedies foreseen in the ICSID normative framework; and, on the other side, the problems of coherence inside the ICSID system as well as in relation to General International Law.

Keywords: coherence, inherent powers, reconsideration, general principles of law, ICSID arbitration.
\end{abstract}

Sumario: I. Introducción. II. Los principios generales de derecho internacional procesal relevantes en materia de reconsideración. 1. La buena administración de justicia y los poderes inherentes de los jueces y árbitros. A) Práctica de ámbito universal. B) Práctica de ámbito sectorial en el CIADI. 2. La cosa juzgada como garantía del carácter definitivo y obligatorio de las sentencias y laudos. A) El concepto de cosa juzgada. B) La naturaleza jurídica de la cosa juzgada. C) La cosa juzgada como principio general en la normativa del CIADI. III. Las particularidades procesales en la normativa del CIADI. 1. La diferenciación entre "decisión" y "laudo": una manifestación del carácter particular de la normativa del CIADI. 2. Las distintas aproximaciones al principio de cosa juzgada en la práctica arbitral. A) Una interpretación extensiva y generalista. B) Una interpretación restrictiva y particularista. IV. La reconsideración como herramienta que promueve la buena administración de justicia. 1. 
Los recursos como garantía de justicia. 2. La reconsideración de una decisión preliminar: ¿un poder inherente en aras de una buena administración de justicia o una actuación ultra vires de los órganos arbitrales? A) La reconsideración como poder inherente necesario para la buena administración de justicia. B) La reconsideración como ejercicio ultra vires de las facultades del órgano arbitral. C) La reconsideración como un poder limitado para garantizar la eficacia del proceso y la corrección del laudo. 3. La reconsideración: ¿una apelación de facto? V. Conclusiones.

\section{Introducción}

1. El aumento del volumen normativo y la especialización que viene experimentando el Derecho Internacional (DI) Público desde hace ya más de medio siglo ha generado lo que se conoce como regímenes autónomos o "self-contained regimes", ${ }^{1}$ es decir, sectores normativos altamente especializados que cuentan en muchos casos con sus propios sistemas de solución de controversias. Aunque esta sectorialización del DI puede considerarse un progreso en el desarrollo de este ordenamiento jurídico e incluso un fenómeno natural al calor de los cambios que se producen en la sociedad internacional, ${ }^{2}$ también entraña ciertos desafíos para la unidad del sistema internacional, lo que generalmente se ha conocido como riesgos de "fragmentación" del DI. ${ }^{3}$

2. El término "fragmentación" está cayendo en desuso actualmente, pero los riesgos de erosión de la unidad del DI persisten y se pueden materializar, por ejemplo, cuando órganos jurisdiccionales ubicados en distintos sectores normativos interpretan la misma norma o principio de manera diversa en situaciones fácticas o jurídicas análogas sin que esté justificado. Asimismo, este escenario se puede reproducir en un sector normativo como el DI de las inversiones, cuyo sistema de solución de las controversias está descentralizado. ${ }^{4}$

3. En este trabajo reflexionamos sobre los problemas de coherencia y consistencia que pueden surgir en el DI de las inversiones desde una perspectiva procesal a la luz de las decisiones que varios órganos arbitrales del CIADI han dictado en los últimos años en relación con una posible facultad de "reconsideración" de las decisiones preliminares o interlocutorias. La reconsideración de estas decisiones no es una facultad prevista expresamente en la normativa CIADI, por lo que se ha tratado en la práctica como un poder inherente de los órganos arbitrales que, aunque puede ser necesario para garantizar una buena administración de justicia, pone en tensión las costuras del principio de cosa juzgada. ${ }^{5}$

\footnotetext{
${ }^{1}$ Para una definición de "self-contained regime", ver M. KosKenNIEMI, "Fragmentation of International Law - The Function and Scope of the Lex Specialis Rule and the Question of 'self-Contained Regimes': An Outline", Transnational Dispute Management, $\mathrm{n}^{\circ}$ 1, 2009, 10 pp., pp. 8-9.

${ }^{2}$ Ver F. Pascual-Vives, Consensus-Based Interpretation of Regional Human Rights Treaties, Leiden/Boston, Brill/Nijhoff, 2019, p. 52: "In conclusion, specialization and sectoralization influence the evolution of contemporary international law. Both phenomena should not be viewed with suspicion or rejection. They are sign of the good health of public international law, (...)" [Se omite nota al pie].

${ }^{3}$ Este tema se incluyó en el programa de trabajo a largo plazo de la CDI en el año 2000 y en 2002 se estableció un Grupo de Estudio para examinar el tema: ver "Fragmentación del Derecho Internacional: Dificultades derivadas de la diversificación y expansión del Derecho Internacional”, Anuario de la Comisión de Derecho Internacional, vol. II, 2a parte, 2002; e "Informe de la Comisión a la Asamblea General en su quincuagésimo cuarto período de sesiones", A/57/10, párrs. 489-513. El informe del Grupo de Estudio puede consultarse en Anuario de la Comisión de Derecho Internacional, vol. II, 2a parte, 2006; e "Informe de la Comisión a la Asamblea General en su quincuagésimo octavo período de sesiones”, A/61/10, párrs. 233-251.

${ }^{4}$ Comisión de las Naciones Unidas para el Derecho Mercantil Internacional (CNUDMI), A/CN.9/WG.III/WP.150, de 28 de agosto de 2018, párrs. 7 y 11. Este tipo de problemas de coherencia y uniformidad están siendo objeto de debate en la CNUDMI a la luz de una posible reforma del sistema de solución de controversias entre inversores y Estados. Véanse los distintos documentos e informes del Grupo de Trabajo III. En https://uncitral.un.org/es/working groups/3/investor-state

${ }^{5}$ Hay tres trabajos recientes en la doctrina, ninguno en lengua española, que han tratado la reconsideración desde diferentes enfoques: ver L.M. BoHMER, "Finality in ICSID Arbitration Revisited, ICSID Review, vol. 31, no 1, 2016, 236-245; T. Cantelmo, "The Inherent Power of Reconsideration in Recent ICSID Case Law", Journal of World Investment and Trade, vol. 18, 2017, 232-270; C. TiтI, "Res Iudicata and Interlocutory Decisions under the ICSID Convention: Antinomies over
} 
4. Mientras algunos órganos arbitrales han negado la posibilidad de reconsiderar una decisión preliminar, posicionándose a favor del principio de cosa juzgada, otros la han reconocido en fechas más recientes dando más relevancia al principio de buena administración de justicia. A la luz precisamente de esta última práctica arbitral, conviene reflexionar sobre el impacto de esta nueva facultad para el actual sistema de recursos del CIADI, especialmente en un momento en el que se está planteando una posible reforma del sistema de solución de controversias entre inversores y Estados, siendo una de las propuestas la creación de un mecanismo de apelación. ${ }^{6}$

5. Las diferentes interpretaciones que han realizado estos tribunales sobre el principio de cosa juzgada y el alcance de los poderes inherentes de los órganos arbitrales al tratar la reconsideración, además, nos permiten estudiar los efectos de la sectorialización del DI desde dos perspectivas. La primera, desde una perspectiva intrasistémica, es decir, desde la coherencia y consistencia de las decisiones en el seno del CIADI; y, la segunda, desde una perspectiva intersistémica, ${ }^{7}$ estudiando las sinergias que se producen entre el DI general y un sector tan especializado como es el DI de las inversiones. ${ }^{8}$ También desde una perspectiva eminentemente procesal, analizando la interacción entre los distintos principios generales que concurren en el procedimiento arbitral, puede valorarse el grado de especialización normativa alcanzado por el DI de las inversiones, así como su compatibilidad con las normas procesales establecidas en el DI general.

6. En el apartado II del trabajo se estudian los principios generales del derecho procesal que subyacen a las decisiones adoptadas por estos tribunales arbitrales al poner en práctica la reconsideración. En el apartado III se exponen las particularidades que presenta el sistema CIADI y que podrían justificar las decisiones adoptadas por algunos órganos arbitrales en materia de reconsideración. En el apartado IV examinamos la reconsideración como poder inherente de los tribunales arbitrales, así como sus límites y causas de acuerdo con la práctica arbitral más reciente y se reflexiona sobre la reconsideración en relación con la apelación. Por último, en el apartado V se exponen las conclusiones alcanzadas.

the Power of Tribunals to Review", ICSID Review, vol. 33, n 2, 2018, 358-379. En este trabajo ponemos el énfasis en los problemas de coherencia y consistencia que pueden surgir tanto en el seno del CIADI, como respecto al DI general. Asimismo, nuestro análisis aborda: primero, el examen de las más recientes decisiones dictadas por tribunales del CIADI (que por razones temporales no son abordadas en algunos de los trabajos citados) y que nos ha permitido comprobar la tendencia jurisprudencial en torno a la reconsideración; segundo, una reflexión sobre los principios generales del proceso que a nuestro juicio subyacen a estas decisiones; y, tercero, una valoración de la reconsideración a la luz de las reformas que se están planteando en el sistema de solución de controversias entre inversores y Estados en la CNUDMI. Nuestro estudio sobre la reconsideración surge del proceso de investigación que hemos realizado para la elaboración de nuestra tesis doctoral basada en el estudio comparativo de la revisión en la jurisprudencia internacional, en especial, de la interpretación y aplicación de los arts. 51 Convenio CIADI y 61 del Estatuto de la CIJ. Al estudiar la práctica arbitral del CIADI, nos encontramos con los casos estudiados en este trabajo en los que, como se verá, se llegó a aplicar por analogía la causa prevista en estas disposiciones (descubrimiento de un hecho nuevo).

${ }^{6}$ CNUDMI, A/CN.9/WG.III/WP.185, de 29 de noviembre de 2019.

7 Hemos optado por utilizar los términos "intrasistémico" e "intersistémico" frente a los términos "intersectorial" e "intrasectorial", porque nuestro análisis no sólo se produce en relación con un sector especializado como el DI de las inversiones o entre dos sectores especializados del DI, sino también en relación con el DI general, respecto al cual no es pertinente referirnos como "sector"; además, también es frecuente referirse a los sectores especializados del DI como "subsistemas", por lo tanto, utilizar el término "sistema" como base para la formación de estas dos categorías nos resulta más correcto.

${ }^{8}$ Algunos autores han estudiado los efectos de la sectorialización para la unidad del DI desde otros sectores particulares, como el DI del Mar o el DI de los Derechos Humanos: ver C. Jiménez Piernas, "La jurisprudencia sobre delimitación de los espacios marinos: una prueba de la unidad del ordenamiento internacional", en E.M. VÁzquez Gómez, M.D. AdAm MuÑoz y N. Cornago-Prieto (eds.), El arreglo pacifico de controversias internacionales, XXIV Jornadas de la Asociación Española de Profesores de Derecho Internacional y Relaciones Internacionales, Valencia, Tirant lo Blanch, 2013, 241-273; y A. PELLET, "Notes sur la "fragmentation" du droit international: Droit des investissements internationaux et Droits de l'Homme", en A. DenIs et al. (eds.), Unity and Diversity of International Law. Essays in Honour of Professor Pierre-Marie Dupuy, Leiden, Brill/ Nijhoff, 2014, 758-784. 


\section{Los principios generales de derecho internacional procesal relevantes en materia de reconsi- deración}

\section{La buena administración de justicia y los poderes inherentes de los jueces y árbitros}

\section{A) Práctica de ámbito universal}

7. El correcto funcionamiento de los órganos jurisdiccionales es esencial para mantener el orden en una sociedad. Además de aplicar el derecho sustantivo al fondo de la controversia, los jueces y tribunales deben velar por que el procedimiento se desarrolle adecuadamente, en particular, aplicando las normas y principios procesales que garantizan una buena administración de justicia. La buena administración de justicia es un principio fundamental o constitucional de todo proceso judicial o arbitral ${ }^{9}$ cuyo contenido exacto es difícil de concretar ya que se traduce en muy diferentes situaciones en la práctica, como suele ocurrir con otros principios generales del derecho. ${ }^{10}$

8. En general, puede decirse que es un principio que guía a los jueces en su cometido y que justifica que adopten determinadas medidas durante el proceso que a veces suponen la flexibilización en la aplicación de las normas procesales. ${ }^{11}$ Ello con el fin de que, por ejemplo, las partes tengan las mismas oportunidades de defender su posición, ${ }^{12}$ no se cometan abusos del proceso o se produzcan demoras o retrasos innecesarios en la solución de la controversia. Como afirma Kolb, “(...) the principle essentially means that the Court has the ultimate power and responsibility to ensure that the justice it renders abides by the highest standards of judicial procedure and that at the same time it takes duly into account the legitimate concerns of all the parties to the proceedings." ${ }^{13}$

9. Con el fin de que el procedimiento se desarrolle correctamente, los órganos jurisdiccionales a menudo han invocado unos poderes inherentes que les permiten adoptar ciertas decisiones a lo largo del procedimiento, es decir, en ausencia de una disposición expresa en la normativa procesal aplicable que contemple esa determinada acción. Ciertamente la norma constitutiva de un tribunal o las reglas de procedimiento por él adoptadas no pueden prever todas y cada una de las situaciones que pueden surgir en la práctica, de ahí que en ocasiones sea necesario realizar enmiendas a los textos normativos. Ante un silencio en la norma, no sería razonable que el órgano arbitral o judicial tuviera que esperar a que se llevara a cabo su enmienda, por lo que la doctrina de los poderes inherentes le proporciona la flexibilidad necesaria para que pueda realizar su función. ${ }^{14}$

\footnotetext{
${ }^{9}$ R. Kolb, "Principles of Procedural Law", en A. Zimmerman et al. (eds.), The Statute of the International Court of Justice. A Commentary, $3^{\mathrm{a}}$ ed., Oxford, Oxford University Press, 2019 (e-book), párrs. 22-28.

${ }^{10}$ Como afirma el Juez Cançado Trindade: “(...) To attempt to offer a definition of the sound administration of justice that would encompass all possible situations that could arise would be far too pretentious, and fruitless. An endless diversity of situations may be faced by the ICJ, leading it — in its pursuit of the realization of justice — to deem it fit to have recourse to the principle of the sound administration of justice (la bonne administration de la justice); this general principle, in sum, finds application in the most diverse circumstances.": ver la Opinión separada del Juez Cançado Trindade, p. 196, párr. 20, que acompaña a la Providencia de 17 de abril de 2013, emitida por la CIJ en el marco del caso Certaines activités menées par le Nicaragua dans la région frontalière (Costa Rica c. Nicaragua) et Construction d'une route au Costa Rica le long du fleuve San Juan (Nicaragua c. Costa Rica), arrêt, C.I.J. Recueil 2015, p. 665.

${ }^{11}$ E. Lauterpacht, "Principles of Procedure in International Litigation", Recueil des Cours, vol. 345, 2009, 391-530, p. 436: "(...) it can be said that, in general, there appears to be agreement that the conduct of international tribunals is not, and should not be, marked by emphasis on a strict adherence to the letter of procedural regulation."

${ }^{12}$ Sobre la relación entre la buena administración de justicia y la igualdad de las partes en el proceso: ver la Opinión separada del Juez Cançado Trindade a la Providencia dictada por la CIJ el 17 de abril de 2013, párrs. 19-23.

${ }^{13}$ R. Kolb, loc. cit., párr. 28.

${ }^{14}$ Churchill Mining y Planet Mining Pty Ltd c. Indonesia (Casos CIADI No ARB/12/14 y 12/40), Decisión sobre anulación de 18 de marzo de 2019, párr. 239, letra 10: “(...) The silence of fundamental texts on matters of procedure accounts for the flexibility of these issues before arbitral tribunals and for the necessity to give them considerable leeway in this regard, as the ICSID Convention does. (...)".
} 
10. Por ejemplo, la CIJ ha reconocido que puede corregir errores materiales, entendiendo por estos, errores menores, como pueden ser errores de escritura o cálculo, para cuya corrección no existe actualmente un mecanismo procesal específico en su normativa procesal, a diferencia de algunas normas aplicables a otras jurisdicciones. ${ }^{15}$ Así, en el caso relativo a la Solicitud de revisión y de interpretación del fallo de 24 de febrero de 1982 en el caso relativo a la plataforma continental (Túnez c. Libia), la Corte afirmó:

“(...) Accordingly, in the present Judgment the Court will deal first with the question of admissibility of the request for revision, and will, then, if appropriate in the light of its findings on that matter, examine the request for interpretation, sector by sector, and the request for correction of an error. In this latter respect, it should be observed that Tunisia's request is presented as one for the correction of an "erreur matérielle". The Court does of course have the power to correct, in one of its judgments, any mistakes which might be described as "erreurs matérielles". That power would not normally be exercised by way of a judgment, since the very nature of the correction of such an error excludes any element of contentious procedure; $(\ldots)^{\text {"16 }}$

11. Esta facultad inherente para corregir errores menores ha sido corroborada en la práctica del arbitraje interestatal. En el caso sobre las Tasas a los Usuarios del Aeropuerto de Heathrow (Estados Unidos/Reino Unido), el órgano arbitral resolvió:

"HMG submitted that it was a general principle of international law that, in the absence of expressly conferred power, an international tribunal had no power to modify or interpret its award (O'Connell, International Law, 2nd ed., 1970, at page 1109, citing the Jaworzina Frontier case (P.J.I.C.), Ser. B. No. 8 (1923) at page 38,) although HMG accepted that, even in the absence of any expressly conferred power, an international tribunal has an inherent power to rectify a material error found to exist in its decision, that is one analogous to an error resulting from a slip of the pen or from the miscalculation or miscasting of arithmetical figures, citing the UK-France Continental Shelf (Interpretation) Case (1978) ILR 54 at page $139 .{ }^{17}$

(...) In those circumstances the relevant inherent powers of the Tribunal are extremely limited. Certainly they would extend to the correction of accidental errors even in the absence of Rule 13(2) of the Tribunal's Rules of Procedure: see paragraph $1.32^{18}$ above." 19

12. La posibilidad de corregir este tipo de errores en las sentencias y laudos es una facultad inherente, no prevista en la normativa procesal aplicable y que puede justificarse en beneficio de una buena administración de justicia. ${ }^{20}$ De hecho, una de las manifestaciones del principio de buena administración de justicia es la capacidad de los jueces de colmar las lagunas que la normativa procesal pueda presen-

\footnotetext{
${ }^{15}$ Inter alia, art. 49.2 del Convenio CIADI.

${ }^{16}$ Application for Revision and Interpretation of the Judgment of 24 February 1982 in the Case concerning the Continental Shelf (Tunisia/Libyan Arab Jamahiriya) (Tunisia v. Libyan Arab Jamahiriya), Judgment, I.C.J. Reports 1985, p. 198, párr. 10.

17 United States-United Kingdom Arbitration concerning Heathrow Airport User Charges (United States-United Kingdom), 30 November 1992-2 May 1994. Decision No. 23 of the Tribunal (Supplementary Decisions and Clarifications) (Determination of USG's Request), Decisión de 1 de noviembre de 1993, UNRIAA, vol. XXIV, p. 345, párr. 1.32.

${ }^{18}$ El párrafo 1.32 es precisamente el que acabamos de citar relativo al argumento de Reino Unido.

19 Ibid., p. 353, párr. 2.25 .

${ }^{20}$ Sobre la fuente de estos poderes inherentes: ver Сн. BRown, loc. cit., p. 244: "While the source of inherent powers in international adjudication has not previously been clarified, it is suggested that it lies in the need for international courts to fulfil their judicial functions. These functions are, chiefly, the settlement of international disputes by adjudication, and the proper administration of international justice, although each international court may, in addition, have different functions specific to the regime within which it operates. (...)". T. Cantelmo expone diferentes escuelas de pensamiento sobre los poderes inherentes; una de estas corrientes señala " (...) the widespread application of inherent powers by international courts and tribunals, coupled with the general assent of governments to this practice, has given rise to an 'autonomous notion of inherent powers' of international judicial bodies that now constitutes a general principle of international law. According to this approach, international tribunals may exercise those powers that are deemed necessary for guaranteeing the fair administration of international justice and for protecting their judicial nature." (citando a P. Gaeta): ver T. CANTElmo, loc. cit., p. 249.
} 
tar. ${ }^{21}$ Por lo tanto, entendemos que si ante un error de esta índole el órgano que emitió la decisión no pudiera corregirlo o tuviera que esperar a una enmienda de la norma procesal que incluyera expresamente tal posibilidad, estaríamos ante un funcionamiento poco eficiente de los órganos jurisdiccionales que conduciría bien a retrasos innecesarios en la ejecución de las decisiones, bien a mantener una decisión que adolece de errores.

13. Pero a veces se han invocado poderes inherentes que van más allá de la corrección de un simple error material. En el arbitraje por comisión mixta constituida entre Estados Unidos y Alemania, en el conocido como caso de los Sabotajes, el superárbitro, O.J. Roberts, afirmó la necesidad de "revisar" una decisión arbitral en caso de fraude y determinados errores en la administración de justicia, siempre que el tribunal no estuviera functus officio. ${ }^{22}$ También en un arbitraje ante la comisión mixta de reclamaciones entre Estados Unidos y Alemania (Philadephia-Girard National Bank (Estados Unidos) c. Alemania y Direktion der Disconto Gesellschaft), tras afirmar que las reglas de procedimiento de esta comisión no contemplaban ninguna disposición sobre la reconsideración de las decisiones dictadas durante el procedimiento, como un laudo parcial, la Comisión estableció unos principios para resolver este tipo de peticiones y, por tanto, dejó la puerta abierta a la posibilidad de reconsiderar la decisión en determinadas circunstancias. ${ }^{23}$

14. Estos errores en la administración de justicia revisten especial trascendencia para la eficacia de la sentencia. Son errores que perjudicarían gravemente los intereses de las partes en litigio ya que habrían obtenido una decisión injusta y que requieren una revisión sustantiva de la decisión afectada. Por tanto, es natural que en este contexto exista mayor discrepancia entre tribunales respecto a la facultad de modificar sustancialmente una decisión que se considera definitiva. ${ }^{24}$

\footnotetext{
${ }^{21}$ R. Kolb, loc. cit., párr. 25.

${ }^{22}$ Lehigh Valley Railroad Company, Agency of Canadian Car and Foundry Company Limited and Various Underwriters (United States) v. Germany, (Sabotage Cases, October 16, 1930), Decisión de 15 de diciembre de 1933, UNRIAA, vol. VIII, 84-460. p. 188: "I think it clear that where the Commission has misinterpreted the evidence, or made a mistake in calculation, or where its decision does not follow its fact findings, or where in any other respect the decision does not comport with the record as made, or where the decision involves a material error of law, the Commission not only has power, but is under the duty, upon a proper showing, to reopen and correct a decision to accord with the facts and the applicable legal rules. My understanding is that the Commission has repeatedly done so where there was a palpable error in its decisions. (...)"; pp. 189-190: "The petition, in short, avers the Commission has been misled by fraud and collusion on the part of witnesses and suppression of evidence on the part of some of them. The Commission is not functus officio. It still sits as a court. To it in that capacity are brought charges that it has been defrauded and misled by perjury, collusion, and suppression. No tribunal worthy its name or of any respect may allow its decision to stand if such allegations are well-founded. Every tribunal has inherent power to reopen and revise a decision induced by fraud. If it may correct its own errors and mistakes, a fortiori it may, while it is still has jurisdiction of a cause, correct errors into which it has been led by fraud and collusion.".

${ }^{23}$ Philadephia-Girard National Bank (United States) v. Germany and Direktion der Disconto Gesellschaft, Impleaded, Decisión de 21 de abril de 1930, UNRIAA, vol. VIII, 69-75, p. 70: "Before taking up the questions raised by this petition, the Commission desires to announce certain principles having general application to petitions and requests for rehearing as to the claims originally listed, by which the Commission will be guided in dealing with this and other similar applications. Where it appears that manifestly the Commission committed an error in its findings of fact on the evidence produced by the Agents at the time the claim was submitted for decision, or in applying the principles of law and the rules of the Commission as established and applied in its previous decisions, the Commission will take under consideration the question of reopening or changing the award. On the other hand, where a rehearing is demanded merely on the ground that by reason of newly submitted evidence the underlying facts were different from those appearing in the record as submitted at the time of the decision, the Commission will not grant a reopening or a reconsideration of the award."

${ }^{24}$ En su Opinión consultiva sobre la Cuestión de Jaworzina, la CPJI declaró que no se podía modificar una decisión de la Conferencia de Embajadores por la que se delimitaba el territorio entre Polonia y Checoslovaquia en tres distritos, sin acuerdo expreso entre las partes: "La mission de la Conférence, ainsi que la Cour l'a déjà remarqué, n'était pas sans analogie avec celle qui incombe à un arbitre, appelé par la confiance de deux Etats à résoudre un conflit de frontières qui les divise. Or à moins d'un accord formel intervenu entre les parties, l'arbitre est sans qualité pour interpréter, et à plus forte raison pour modifier sa sentence en la révisant. La Décision du 28 juillet, acceptée par les Gouvernements polonais et tchécoslovaque ne mentionne aucun accord de cette nature." ; ver Affaire de Jaworzina (Frontière Polono-Tchécoslovaque), avis consultatif du 6 décembre 1923, CPJI, Série B, $n^{\circ} 8$, p. 38.
} 


\section{B) Práctica de ámbito sectorial en el CIADI}

15. La capacidad para actuar en ausencia de una disposición expresa puede estar recogida propiamente en la normativa procesal, como muestra el art. 44 del Convenio CIADI, ${ }^{25}$ que prevé que el tribunal puede resolver cualquier cuestión de procedimiento que surja durante el mismo, o el art. 17 del Reglamento de la CNUDMI, ${ }^{26}$ que establece que el tribunal dirigirá el proceso de la manera más apropiada siempre que se den las mismas oportunidades a las partes para hacer valer sus derechos, poniendo de relieve, como se observa, otro principio general de carácter procesal esencial en todo proceso, que es la igualdad de las partes. Pero también se puede ejercer esta facultad aún sin estar codificada, pues son facultades necesarias para el ejercicio de la función jurisdiccional. ${ }^{27}$

16. Asimismo, existen diferentes opiniones sobre la base jurídica que da cobertura a estos poderes inherentes. ${ }^{28}$ En este trabajo se reflexiona sobre el poder inherente que han ejercido algunos órganos arbitrales constituidos en el seno del CIADI consistente en la posibilidad de "reconsiderar" las decisiones preliminares que emiten a lo largo del procedimiento hasta que se dicta el laudo, como un poder necesario para el cumplimiento de sus funciones como órgano jurisdiccional ${ }^{29} \mathrm{y}$, en particular, para lograr una buena administración de justicia, entendiendo que el tribunal no sólo debe procurar resolver la controversia con eficacia y celeridad, sino también procurar que sea justa. ${ }^{30}$

17. Huelga señalar el riesgo que supone reconocer una facultad como esta cuando no está prevista expresamente en la normativa procesal, pues reabrir cuestiones ya decididas, aunque sea en un momento anterior al laudo, repercute en el desarrollo del procedimiento y produce importantes consecuencias para las partes en la controversia, como es que una cuestión que han dado por resuelta vuelva a ser objeto de examen y pueda dar lugar a un cambio en la situación jurídica previamente establecida.

18. Además, los Estados partes del Convenio CIADI podrían llegar a dudar de la legitimidad de los órganos arbitrales cuando éstos realizan interpretaciones de las cláusulas del Convenio que suponen incluir una nueva vía de modificación de las decisiones, sobre las que ellos no tuvieron oportunidad de pronunciarse cuando manifestaron su consentimiento en obligarse por el Convenio.

${ }^{25}$ Art. 44 del Convenio CIADI, “Todo procedimiento de arbitraje deberá tramitarse según las disposiciones de esta Sección y, salvo acuerdo en contrario de las partes, de conformidad con las Reglas de Arbitraje vigentes en la fecha en que las partes prestaron su consentimiento al arbitraje. Cualquier cuestión de procedimiento no prevista en esta Sección, en las Reglas de Arbitraje o en las demás reglas acordadas por las partes, será resuelta por el Tribunal."

${ }^{26}$ Art. 17.1 del Reglamento de Arbitraje de la CNUDMI, aprobado en 2013, "Con sujeción a lo dispuesto en el presente Reglamento, el tribunal arbitral podrá dirigir el arbitraje del modo que considere apropiado, siempre que se trate a las partes con igualdad y que en cada etapa del procedimiento se dé a cada una de las partes una oportunidad razonable de hacer valer sus derechos. En el ejercicio de su discrecionalidad, el tribunal arbitral dirigirá las actuaciones con miras a evitar demoras y gastos innecesarios y a llegar a una solución justa y eficaz del litigio entre las partes."

${ }^{27}$ Ver la opinión disidente de G. Abi-Saab en ConocoPhillips Petrozuata B.V. y otros c. Venezuela (Caso CIADI N ${ }^{\circ}$ ARB/07/30), Decisión sobre Reconsideración de 10 de marzo de 2014, párr. 56.

28 T. CANTElmo, loc. cit., pp. 246-250; y Ch. Brown, loc. cit., pp. 222-228.

${ }^{29}$ Sobre la necesidad de asegurar el cumplimiento de la función judicial como fuente normativa de los poderes inherentes: ver С H. Brown, loc. cit., pp. 228-229; y RSM Production Corporation c. Granada (Caso CIADI No ARB/05/14), Decisión de 7 de diciembre de 2009, párr. 20: "The Committee agrees with the Applicant that international courts and tribunals have certain inherent powers which permit them to exercise powers that may go beyond the express terms of their constitutive instruments. However, the Committee considers that international courts and tribunals can only exercise such powers where those powers are necessary to ensure the performance of functions that have been expressly conferred. Further, there are limitations on the exercise of inherent powers, including that such powers cannot be inconsistent with the terms of the relevant constitutive instrument of the international court or tribunal."

${ }^{30}$ Según el Juez Cançado Trindade: "The sound administration of justice enables the international tribunal at issue to tackle questions of procedure even if these latter have "escaped" the regulations of its interna corporis. It is, in my perception, the idea of an objective justice that, ultimately, guides the sound administration of justice (la bonne administration de la justice), in the line of jusnaturalist thinking.": ver la Opinión separada del Juez Cançado Trindade a la Providencia dictada por la CIJ el 17 de abril de 2013, párr. 15. 
19. Por otro lado, se debe también tener en cuenta que el ejercicio de una facultad no conferida expresamente en la normativa procesal aplicable podría conducir a procedimientos de anulación contra los laudos emitidos, alegando una extralimitación manifiesta de las facultades del tribunal (art. 52.1.b del Convenio CIADI). ${ }^{31}$ Los límites de estos poderes inherentes no están claramente definidos pues, como señalamos, se traducen en acciones muy diferentes atendiendo a las circunstancias en presencia. En cada caso, el tribunal arbitral o, en su caso, posteriormente el comité ad hoc de anulación han valorado si la medida adoptada encontraba cabida en el ámbito de aplicación del art. 44 del Convenio CIADI o del principio Kompetenz-Kompetenz recogido en el art. 41 del Convenio CIADI o si, por el contrario, era una medida ultra vires $\mathrm{y}$, por tanto, no justificada, como explicaremos más adelante.

20. Los órganos arbitrales, en los casos que estudiamos en este trabajo, han intentado dar respuesta a las solicitudes de reconsideración partiendo de la interpretación del principio de cosa juzgada y de su posible aplicación a las decisiones preliminares en la jurisdicción del CIADI; de ahí que resulte esencial abordar el razonamiento de los tribunales en torno a la cosa juzgada. Además del anterior principio, se ven involucrados otros, como el principio de economía procesal o el principio de buena fe que debe regir la conducta de los litigantes a lo largo de todo el proceso. ${ }^{32}$

\section{La cosa juzgada como garantía del carácter definitivo y obligatorio de las decisiones arbitrales}

\section{A) El concepto de cosa juzgada}

21. El principio procesal de cosa juzgada juega un papel esencial en el ordenamiento jurídico internacional. La práctica totalidad de normas estatutarias y reglamentarias que regulan el procedimiento ante los diferentes tribunales internacionales establecen el carácter final y obligatorio de sus sentencias y laudos, elementos fundamentales del principio de cosa juzgada.

22. La res judicata precluye la posibilidad de que una controversia dilucidada ante un órgano jurisdiccional vuelva a ser objeto de un proceso posterior entre las mismas partes y con el mismo objeto, pudiendo plantearse como una excepción preliminar. ${ }^{33}$ En particular, se afirma que la cosa juzgada tiene dos vertientes, una positiva y otra negativa. Conforme a la vertiente positiva, este principio implica que las decisiones jurisdiccionales son obligatorias y deben cumplirse de buena fe; mientras que en su vertiente negativa supone que la controversia no puede ser objeto de un nuevo litigio. ${ }^{34}$

${ }^{31}$ RSM Production Corporation c. Santa Lucía (Caso CIADI No ARB/12/10), Decisión sobre anulación de 29 de abril de 2019, párrs. 183-201; Churchill Mining y Planet Mining Pty Ltd c. Indonesia, (Casos CIADI No ARB/12/14 y 12/40), Decisión sobre anulación de 18 de marzo de 2019, párrs. 237-239; y, en especial, sobre la facultad de reconsiderar una decisión preliminar, ver Standard Chartered Bank (Hong Kong) Limited c. Tanzania Electric Supply Company Limited (Caso CIADI N ${ }^{\circ}$ ARB/10/20), Decisión sobre anulación de 22 de agosto de 2018, párrs. 316-330.

${ }^{32}$ Como afirma Tanzi: “( (...). Good faith affects legal obligations at each stage, from negotiation to enforcement. In arbitration, it informs the rules of procedure and the powers of the tribunal, which include the determination of its own competence; it also supplements the applicable law and influences its interpretation and application by the tribunal." A. TANZI, "The Relevance of the Foreign Investor's Good Faith”, en A. Gattini, A. TAnZI y F. Fontanelli (eds.), General Principles of Law in International Investment Arbitration, Leiden, Brill-Nijhoff, 2018, 189-220, p. 194.

${ }^{33}$ Es ya una doctrina asentada que, para poder estimar que un fallo se encuentra protegido por el efecto de la cosa juzgada, deben concurrir tres elementos en los procesos implicados: persona, petitum y causa petendi. En su conocida opinión disidente en el caso de la Demanda de interpretación de las Sentencias núm. 7 y núm. 8 relativas al Caso de la Fábrica de Chorzów, sustanciado ante la CPJI, el Juez D. Anzilotti expuso la triple identidad (tres elementos tradicionales de identificación) que debía darse para poder comprobar si una decisión gozaba del efecto de cosa juzgada: persona, petitum y causa petendi: ver Interprétation des arrêts Nos. 7 et 8 (Usine de Chorzów), arret du 16 décembre 1927, C.P.J.I., Série A, $n^{\circ} 13$, p. 23, párr. I. Posteriormente, la CIJ ha establecido que no es suficiente comprobar que se da identidad de estos tres elementos, sino que también importa determinar si la cuestión objeto del nuevo proceso ha sido decidida con carácter definitivo por la Corte en el proceso anterior al que se hace referencia: ver Question de la délimitation du plateau continental entre le Nicaragua et la Colombie au-delà de 200 milles marins de la côte nicaraguayenne (Nicaragua c. Colombie), exceptions préliminaires, arrêt, C.I.J. Recueil 2016, p. 126, párrs. 55 y 59.

${ }^{34}$ W.S. Dodge, "Res judicata", en R. Wolfrum (ed.), The Max Planck Encyclopedia of Public International Law, (OUP last updated January 2006), párr. 1. 
23. Este principio es esencial para garantizar el funcionamiento eficaz de la justicia internacional. Por un lado, para las partes en litigio el efecto de cosa juzgada proporciona estabilidad y previsibilidad respecto a los derechos y obligaciones que el juez ha determinado en su fallo, evitando que la situación jurídica declarada por el fallo no se vea alterada en un futuro. Por otro, como ya afirmara $\mathrm{Ch}$. De Visscher, la autoridad de la cosa juzgada reside en una necesidad social, manifestada en la máxima latina interest reipublicae ut sit finis litium. ${ }^{35}$

24. En efecto, el principio de cosa juzgada, también presente en la mayoría de los ordenamientos jurídicos nacionales, tiene, si cabe, mayor importancia para el mantenimiento del orden y la seguridad en la sociedad internacional. Desde los primeros procesos arbitrales internacionales, el objetivo primordial del sometimiento de las controversias entre Estados a un medio de arreglo jurisdiccional ha sido poner fin a las mismas de manera definitiva evitando que se perpetuaran en el tiempo, lo que, sin duda, supone un riesgo para la paz y seguridad internacionales..$^{36}$ Ello se observa en las cláusulas sobre arreglo de las controversias contenidas en tratados internacionales sobre amistad, comercio y navegación del siglo XIX que establecían el carácter final y concluyente de las disputas, así como en la ausencia de recursos contra las decisiones de los órganos a los que se sometía la disputa, en aquel momento, las llamadas comisiones mixtas. ${ }^{37}$

25. En la jurisdicción de la CIJ, el principio de cosa juzgada se desprende del efecto combinado que producen los arts. 59, 60 y 61 del Estatuto de la CIJ. ${ }^{38} \mathrm{El}$ art. 59 dispone, en forma negativa, que los fallos de la Corte son obligatorios para las partes en litigio y respecto a la controversia concreta, por lo que puede decirse que allí se reconoce un efecto de cosa juzgada relativa. El art. 60 impone la finalidad del fallo y la imposibilidad de apelación, de lo que se desprende que la regla general es su firmeza e invariabilidad. Por último, el art. 61 prevé la posibilidad de la revisión del fallo, aunque sometida a unas condiciones tasadas, lo que refuerza el carácter obligatorio y definitivo previsto en las disposiciones anteriores y plantea la revisión como una excepción a la regla general. Asimismo, dado que la CIJ es el órgano judicial principal de la Organización de las Naciones Unidas, es necesario mencionar que el art. 94.1 de la Carta de la ONU establece la obligación de cumplir con los fallos de la CIJ a sus Estados miembros, cuando estos últimos sean partes en un litigio sustanciado ante este órgano judicial.

${ }^{35}$ CH. De Visscher, "La chose jugée devant la Cour Internationale de La Haye", Revue belge de droit international, vol. I, 1965, 5-14, p. 5: "Le fondement de l'autorité de la chose jugée réside dans sa nécessité sociale. Il est de l'intérêt général que les litiges ne recommencent pas indéfiniment relativement au même objet: ut sit finis litium. La présomption légale de vérité qui s'y attache est, s'il se peut, plus impérative encore dans les rapports entre Etats que dans l'ordre interne."

${ }^{36}$ La CIJ ha definido los dos propósitos de la res judicata de la siguiente manera: "Two purposes, one general, the other specific, underlie the principle of res judicata, internationally as nationally. First, the stability of legal relations requires that litigation come to an end. The Court's function, according to Article 38 of its Statute, is to "decide", that is, to bring to an end, "such disputes as are submitted to it". Secondly, it is in the interest of each party that an issue which has already been adjudicated in favour of that party be not argued again. Article 60 of the Statute articulates this finality of judgments. Depriving a litigant of the benefit of a judgment it has already obtained must in general be seen as a breach of the principles governing the legal settlement of disputes.": ver Application of the Convention on the Prevention and Punishment of the Crime of Genocide (Bosnia and Herzegovina v. Serbia and Montenegro), Judgment, I.C.J. Reports 2007, párr. 116.

${ }^{37}$ Véase el art. V del Tratado de amistad, comercio y navegación, de 19 de noviembre de 1794 (“Tratado Jay”), celebrado entre los Estados Unidos de América y Gran Bretaña, "And both parties agree to consider such decision as final and conclusive, so as to the same shall never thereafter be called into question, or made the subject of dispute or difference between them." También se repite esta cláusula en los arts. VI y VII: ver el texto completo del tratado en J.B. DAVIs, Treaties and Conventions concluded between the United States of America and other Powers, since July 4 1776, Washington D.C., Government Printing Office, 1889 , pp. 379-395.

${ }^{38}$ Ch. Brown, “Article 59”, en A. Zimmerman et al. (eds.). The Statute of the International Court of Justice. A Commentary, $3^{\text {a }}$ ed., Oxford, Oxford University Press, 2019 (e-book), párrs. 32-33; S. Rosenne, Interpretation, Revision and Other Recourse from International Judgments and Awards, Leiden/Boston, Martinus Nijhoff, 2007, pp. 43-44; R. GeIss, "Revision Proceedings Before the International Court of Justice", Zeitschrift für ausländisches öffentliches Recht und Völkerrecht, vol. 63, 2003, $167-$ 194, p. 172; y M.N. SHaw, "Statute, Article 60: the Res Judicata", en Rosenne's Law and Practice of the International Court: 1920-2015, Brill, (e-book), vol. 3, capítulo 27, párr. 391. 


\section{B) La naturaleza jurídica de la cosa juzgada}

26. En cuanto a la naturaleza de esta regla procesal, la cosa juzgada constituye un principio general del derecho, ${ }^{39}$ como viene declarando la CIJ en su práctica contenciosa y consultiva. ${ }^{40}$ Recientemente, la CIJ se pronunció sobre la excepción preliminar de cosa juzgada planteada en el caso relativo a la Cuestión de la delimitación de la plataforma continental entre Nicaragua y Colombia más allá de las 200 millas marinas contadas desde la costa de Nicaragua (Nicaragua c. Colombia). Colombia alegó esta excepción, ya que sostenía que las cuestiones sometidas a la decisión de la CIJ por parte de Nicaragua ya habían sido decididas en un fallo de la Corte en $2012 .{ }^{41}$ Sobre la cosa juzgada, la Corte afirmó:

"La Cour rappelle que le principe de l'autorité de la chose jugée, tel que réflété aux articles 59 et 60 de son Statut, est un principe général de droit qui protège en même temps la fonction judiciaire d'une cour ou d'un tribunal et les parties à une affaire qui a donné lieu à un jugement définitif et sans recours. (...)"42

27. Para poder determinar si la reclamación de Nicaragua en el presente proceso ya había sido decidida por medio de un fallo anterior, la Corte no sólo abordó la necesidad de comprobar la identidad de los tres elementos tradicionales -persona, petitum y causa petendi- sino que tuvo que analizar el contenido de su decisión para constatar si la pretensión de Nicaragua había sido ya decidida con carácter definitivo en el fallo de 2012, pues los Estados en litigio presentaron opiniones divergentes sobre el alcance de uno de los pronunciamientos contenidos en la parte dispositiva del fallo, lo que llevó a la Corte a tener que aclarar el sentido del fallo. La Corte concluyó que su pretensión no había sido resuelta en el fallo anterior y, por tanto, desestimó la excepción planteada por Colombia. Sin embargo, interesa señalar que fue una decisión controvertida, pues este pronunciamiento se adoptó por empate de votos entre los miembros de la Corte y fue necesario el voto de calidad del Presidente, R. Abraham. ${ }^{43}$ Algunos de los Jueces disidentes expresaron la importancia de preservar la cosa juzgada de los fallos poniendo fin a las disputas entre Estados, pues lo contrario supondría un perjuicio para la estabilidad, certeza y finalidad de las decisiones judiciales. ${ }^{44}$ Asimismo, se refirieron a la cosa juzgada como un principio reconocido en todo sistema jurídico, si bien con diferentes nombres o formas. ${ }^{45}$ Por tanto, la cosa juzgada puede considerarse un principio general del derecho, ampliamente reconocido por los Estados y aplicado por los tribunales internacionales. ${ }^{46}$

\footnotetext{
${ }^{39}$ En el arbitraje interestatal también se ha aludido a la cosa juzgada como principio generalmente aceptado y aplicable en la jurisdicción internacional: ver The Pious Fund of the Californias (Estados Unidos de América c. Estados Unidos de México) (Caso CPA No 1902-01), Sentencia de 14 de octubre de 1902, p. 2. Disponible en la página web de la CPA, https://pca-cpa.org/ en/home/

${ }^{40}$ Effect of awards of compensation made by the U.N. Administrative Tribunal, Advisory Opinion of July 13 ${ }^{\text {th }}$, 1954: I.C.J. Reports 1954, p. 53: "According to a well-established and generally recognized principle of law, a judgment rendered by such a judicial body is res judicata and has binding force between the parties to the dispute. (...)"; en el caso Demande en interprétation de l'arrêt du 11 juin 1998 en l'affaire de la Frontière terrestre et maritime entre le Cameroun et le Nigéria (Cameroun c. Nigéria), exceptions préliminaires (Nigéria c. Cameroun), arrêt, C.I.J. Recueil 1999, p. 36, párr. 12, la Corte también se refirió a la cosa juzgada como un "principio": "Le libellé et la structure de l'article 60 traduisent la primauté du principe de l'autorité de la chose jugée. Ce principe doit être préservé."

${ }^{41}$ Territorial and Maritime Dispute (Nicaragua v. Colombia), Judgment, I.C.J. Reports 2012, p. 624.

${ }^{42}$ Question de la délimitation du plateau continental entre le Nicaragua et la Colombie au-delà de 200 milles marins de la côte nicaraguayenne (Nicaragua c. Colombie), exceptions préliminaires, arrêt, C.I.J. Recueil 2016, p. 26, párr. 58.

${ }^{43}$ Este pronunciamiento se aprobó por ocho votos contra ocho, por el voto de calidad del Presidente. Los Jueces disidentes Yusuf (Vicepresidente), Cançado Trindade, Xue, Donoghue, Gaja, Bhandari, Robinson y el Juez ad hoc Brower emitieron una opinión disidente conjunta.

${ }^{44}$ Opinión disidente conjunta del Vicepresidente Yusuf, de los Jueces Cançado Trindade, Xue, Gaja, Bhandari, Robinson y del Juez ad hoc Brower, p. 162, párr. 67.

${ }^{45}$ Ibid., pp. 142-143, párr. 4.

${ }^{46}$ J. CRaWford, Brownlie's principles of public international law, Oxford, Oxford University Press, 2019 (e-book), Parte I, capítulo 2, afirma: “(...) But the most frequent and successful use of domestic law analogies has been in the field of evidence, procedure, and jurisdiction. Thus, there have been references to the rule that no one can be judge in his own suit, to litispendence, to res judicata, to various 'principles governing the judicial process', and to 'the principle universally accepted by international tribunals ... to the effect that the parties to a case must abstain from any measure capable of exercising a prejudicial
} 
28. Actualmente, el tema de los principios generales del derecho en el sentido del art. $38.1 \mathrm{c}$ ) del Estatuto de la CIJ forma parte del programa de trabajo de Comisión de Derecho Internacional. Entre los principios generales aludidos en el primer informe elaborado por el Relator Especial, M. Vázquez-Bermúdez, se encuentra el principio de cosa juzgada, citado en relación con ejemplos de la práctica judicial y arbitral internacionales ${ }^{47}$ Conviene señalar que se trata de un primer informe que sienta las bases sobre el objeto de estudio, por lo que cuestiones esenciales sobre este tema se abordarán en futuros informes, como las funciones de los principios generales y su relación con otras fuentes del derecho internacional o su concreta determinación y el requisito de su reconocimiento, necesario para poder constatar su existencia como tales. No obstante, parece que la cosa juzgada no suscita dudas sobre su consideración como principio general del derecho, pues cuenta con el reconocimiento general de los Estados y es aplicable en la justicia internacional. ${ }^{48}$

\section{C) La cosa juzgada como principio general en la normativa del CIADI}

29. Este principio general ha sido reconocido y aceptado también en el sector particular del DI de las inversiones. ${ }^{49}$ En la normativa del CIADI, este principio se desprende del art. 53 del Convenio CIADI que declara la obligatoriedad del laudo para las partes en la controversia y la imposibilidad de apelación. ${ }^{50}$ Por tanto, el laudo arbitral, igual que los fallos de la CIJ, posee efecto de cosa juzgada, con las consecuencias jurídicas que ello implica respecto a futuros procesos, como ya indicamos, cuando se da la identidad de persona, petitum y causa petendi. ${ }^{51}$

30. Asimismo, es importante recordar la ausencia de una doctrina del precedente vinculante (stare decisis) tanto en la jurisdicción de la CIJ como del CIADI. ${ }^{52}$ El CIADI, donde existe una mayor variabilidad en la composición del tribunal debido a la naturaleza ad hoc de los órganos arbitrales, es un sistema más susceptible a cambios de sentido en las decisiones. Como señala C.J. Tams: "The risk of in-

effect in regard to the execution of the decision to be given"”; W.S. DoDGE, loc. cit., párr. 3: "Res iudicata is widely accepted and applied by international courts and tribunals."; V. Lowe, "Res judicata and the rule of law in international arbitration", African Journal of International Law and Comparative Law, vol. 8, 1996, 38-50, p. 39: "Res judicata is also a general principle of international law (...)". También se incluye la res judicata como un principio existente y aplicado en la jurisdicción internacional, así como en los ordenamientos internos: ver G. GAJA, "General Principles of Law”, en R. Wolfrum, (ed.), The Max Planck Encyclopedia of Public International Law, (OUP last updated May 2013), párrs. 11 y 26; y R. KolB, loc. cit., párr. 8.

${ }^{47}$ Primer informe sobre los principios generales del derecho, A/CN.4/732, de 5 de abril de 2019, p. 39 y, en particular, las notas al pie 216 y 219 y p. 42. Interesa destacar un apunte del Relator Especial respecto al principio de cosa juzgada: "Puede darse el caso de que una norma de derecho internacional convencional o consuetudinario trate la misma cuestión que un principio general del derecho. Un ejemplo de ello es el principio de la cosa juzgada aplicado por la Corte Internacional de Justicia, que, aunque a menudo se invoca como principio general del derecho, también está conectado con los Artículos 59,60 y 61 del Estatuto de la Corte. En tales casos, puede ser necesario detenerse y preguntarse si la Corte está aplicando un principio general del derecho o una norma de un tratado, o ambas cosas al mismo tiempo.”: ver p. 10, nota al pie 26.

${ }^{48}$ Estos dos factores que se enuncian en el primer informe del Relator Especial serán estudiados y aclarados en futuros informes: ver Primer informe sobre los principios generales del derecho, A/CN.4/732, de 5 de abril de 2019, párrs. 169-170.

${ }^{49}$ P. JANIG y A. ReINISCH, "General Principles and the Coherence of International Investment Law: of Res Judicata, Lis Pendens and the Value of Precedents", en M. Andenas et al. (eds.), General Principles and the Coherence of International Investment Law, Leiden, Brill-Nijhoff, 2019, (e-book), 247-296, pp. 256-257.

${ }^{50}$ Art. 53 del Convenio CIADI: "El laudo será obligatorio para las partes y no podrá ser objeto de apelación ni de cualquier otro recurso, excepto en los casos previstos en este Convenio. Las partes lo acatarán y cumplirán en todos sus términos, salvo en la medida en que se suspenda su ejecución, de acuerdo con lo establecido en las correspondientes cláusulas de este Convenio."

${ }^{51}$ P. JANIG y A. ReInISCH, loc. cit., pp. 259-263.

${ }^{52}$ CH.H. Schreuer et al., The ICSID Convention: A Commentary, $2^{\mathrm{a}}$ ed., Cambridge, Cambridge University Press, 2009, p. 1102, párr. 17: "The lack of a system of stare decisis implies a certain risk of inconsistent awards". Sobre el papel del precedente en el arbitraje de inversiones: ver P. JANIG y A. REINISCH, loc. cit., pp. 270-275; A. Rigo Sureda, Investment Treaty Arbitration. Judging Under Uncertainty, Cambridge, Cambridge University Press, 2012, pp. 109-131; Сh.H. SCHREUER y M. WeINIger, “Conversations Across Cases - Is there a Doctrine of Precedent in Investment Arbitration?", Transnational Dispute Management, $\mathrm{n}^{\circ}$ 3, 2008, 18 pp., pp. 1-18; y A. PAStor PALOMAR, "Relativismo y consistencia en la jurisprudencia reciente del CIADI, con especial referencia a los casos contra Argentina”, en C.R. FERnÁndez Liesa (dir.), Tribunales internacionales y espacio iberoamericano, Pamplona, Aranzadi, 2009, 245-262, pp. 246-247. 
consistent decisions therefore is inherent in the system; it is part and parcel of a process of decentralised, non-hierarchical, and ad hoc dispute resolution, such as that of investment arbitration." ${ }^{53}$

31. No obstante, aunque los órganos arbitrales han señalado que, efectivamente, no están obligados en su función a seguir las decisiones anteriores de otros tribunales, también han resaltado la importancia de tomar como referencia los laudos y decisiones previas para garantizar el "desarrollo armonioso" del DI de las inversiones. ${ }^{54}$ Sin duda, esta práctica arbitral en materia de inversiones favorece la coherencia de este sector normativo, pero trasciende más allá de este sector cuando, además de tomar como referencia las decisiones y laudos en materia de inversiones, los órganos arbitrales se inspiran en las sentencias de otros órganos jurisdiccionales internacionales como la CIJ.

32. En suma, la diferente naturaleza y características del arbitraje respecto a la jurisdicción permanente conlleva que los órganos arbitrales puedan interpretar una norma o principio de manera diferente, tanto entre ellos, es decir, desde una perspectiva intrasistémica, como en relación con otro órgano jurisdiccional, como la CIJ, lo que podría denominarse una perspectiva intersistémica. En ocasiones, esta diferencia en la interpretación de la norma puede deberse, no a la aplicación de criterios interpretativos distintos, sino, precisamente, a las particularidades que presenta una jurisdicción especializada, como es el arbitraje CIADI.

\section{Las particularidades procesales en la normativa del CIADI}

\section{La diferenciación entre "decisión" y "laudo": una manifestación del carácter particular de la normativa del CIADI}

33. En el marco jurídico del CIADI se distingue entre "decisión" y "laudo". Conforme a la normativa del CIADI, las excepciones preliminares ${ }^{55}$ se resuelven mediante laudo cuando el tribunal concluye que el Centro no tiene jurisdicción y el tribunal no es competente para conocer de la controversia (Regla 41.6 de las Reglas de Arbitraje del CIADI) ${ }^{56}$ o cuando decide resolverlas junto con el fondo del asunto (art. 41.2 del Convenio CIADI), ${ }^{57}$ ya que las cuestiones de fondo controvertidas se deciden por

${ }^{53}$ C.J. TAMs, “An appealing option? The debate about an ICSID appellate structure”, Transnational Dispute Management, $\mathrm{n}^{\mathrm{o}}$ 5, 2007, 60 pp., p. 23.

${ }^{54}$ Ver inter alia EDF International S.A., SAUR International S.A. y León Participaciones Argentinas S.A. c. Argentina (Caso CIADI No ARB/03/23), Decisión sobre anulación de 5 de febrero de 2016, párr. 295; Suez, Sociedad General de Aguas de Barcelona S.A. y Vivendi Universal S.A c. Argentina (Caso CIADI No ARB/03/19), Decisión sobre anulación de 5 de mayo de 2017, párr. 76; y Burlington Resources, Inc. c. Ecuador (Caso CIADI No ARB/08/5), Decisión sobre reconsideración y Laudo de 7 de febrero de 2017, párr. 46. Conviene señalar que, en este último caso, la árbitra B. Stern disentía de la opinión de la mayoría sobre este aspecto: "Tal como se expresara en las Decisiones sobre Jurisdicción y Responsabilidad, el Tribunal considera que no está obligado a seguir las decisiones anteriores de tribunales internacionales. Sin embargo, la mayoría considera que, siempre con sujeción a las particularidades de un tratado determinado y a las circunstancias del caso, tiene el deber de adoptar soluciones establecidas en una serie de casos similares consistentes, si existieran, a menos que existan motivos convincentes en contrario. La árbitra B. Stern no percibe el rol de los árbitros de la misma manera, ya que considera que es su deber decidir cada caso exclusivamente de acuerdo a sus propios méritos, tal como se argumentara ante ella, con independencia de cualquier tendencia jurisprudencial aparente." (párr. 46).

${ }^{55}$ С H.H. Schreuer et al., op. cit., p. 535, párr. 69: "The Tribunal has essentially three possibilities to deal with jurisdictional questions: first, it may decide the question by way of a separate preliminary decision; second, it may decide the question as part of the award on the merits; and third, it may make a finding that it does not have jurisdiction, a decision that is final by definition and hence an award."

${ }^{56}$ Art. 41.6 de las Reglas de Arbitraje del CIADI, "Si el Tribunal decidiere que la diferencia no cae dentro de la jurisdicción del Centro, o que no es de su competencia, o que todas las reclamaciones carecen manifiestamente de mérito jurídico, dictará laudo a tal efecto."

${ }^{57}$ Art. 41.2 del Convenio CIADI, "Toda alegación de una parte que la diferencia cae fuera de los límites de la jurisdicción del Centro, o que por otras razones el Tribunal no es competente para oírla, se considerará por el tribunal, el que determinará si ha de resolverla como cuestión previa o conjuntamente con el fondo de la cuestión.”. El comentario que acompaña a este artículo dice: "(...) If jurisdictional questions are joined to the merits (...), they will be decided as part of the final award.” Сн.н. SCHREUER et al., op. cit., p. 536, párr. 72. 
medio de laudo (art. 48.3 del Convenio CIADI).$^{58}$ No obstante, un órgano arbitral también puede decidir sobre competencia y jurisdicción mediante una decisión con carácter previo al laudo en la que ratifique la jurisdicción del Centro y la competencia del tribunal, incorporándose posteriormente al laudo definitivo conforme establece el art. 48.3 del Convenio CIADI. ${ }^{59}$

34. La diferenciación entre "laudo" y "decisión" fue aclarada por el tribunal arbitral en Burlington Resources c. Ecuador, con ocasión de la solicitud de reconsideración de la Decisión sobre responsabilidad dictada con anterioridad por este mismo tribunal, planteada por Ecuador:

“(...) El término "laudo" se reserva para la decisión que pone fin al arbitraje, lo que, en virtud de otros regímenes, se denomina laudo definitivo. Entonces, a modo de ejemplo, una decisión que rechaza la jurisdicción respecto de la controversia en su totalidad (Regla 41(6) de las Reglas de Arbitraje) o una decisión sobre el fondo que resuelve todas las reclamaciones o todas las reclamaciones pendientes ante el Tribunal constituye un "laudo" (Artículo 48(3) del Convenio CIADI). Por otro lado, una decisión preliminar que confirma la jurisdicción o resuelve otras cuestiones que surgen "de camino" al laudo definitivo, p. ej., en materia de derecho aplicable o responsabilidad, o parte de las reclamaciones, constituye una "decisión" (anterior al laudo) a efectos del CIADI. Bajo otros regímenes, estas decisiones serían designadas por términos tales como laudos provisionales, preliminares, interlocutorios o parciales. ${ }^{" 60}$

35. Esta diferencia no se da en la jurisdicción de la CIJ, ya que la Corte decide sobre las excepciones preliminares, sobre el fondo, así como sobre los procedimientos de interpretación o revisión por medio siempre de un fallo, ${ }^{61}$ que adquiere fuerza de cosa juzgada en virtud de los arts. 59 y 60 del Estatuto de la CIJ, los cuales no diferencian entre decisiones sobre excepciones preliminares y decisiones sobre el fondo. ${ }^{62}$ En la jurisdicción del CIADI es oportuno apuntar que, aunque en los procedimientos de acla-

${ }^{58}$ Art. 48.3 del Convenio CIADI, "El laudo contendrá declaración sobre todas las pretensiones sometidas por las partes al tribunal y será motivado."

${ }^{59}$ Ver, inter alia, Burlington Resources, Inc. c. Ecuador (Caso CIADI No ARB/08/5), Decisión sobre Reconsideración y Laudo de 7 de febrero de 2017, párr. 86; y Electrabel S.A. c. Hungría (Caso CIADI No ARB/07/19), Laudo de 25 de noviembre de 2015, párr. 4. También, Ch.H. Schreuer et al., op. cit., pp. 537-538, párrs. 77-78.

${ }^{60}$ Burlington Resources, Inc. c. Ecuador (Caso CIADI No ARB/08/5), Decisión sobre Reconsideración y Laudo de 7 de febrero de 2017, párr. 82.

${ }^{61}$ El art. 79.9 del Reglamento de la CIJ, sobre excepciones preliminares, establece que estas se decidirán por medio de fallo. Ahora bien, como se sabe, la Corte también puede dictar providencias cuyo objetivo es el buen desarrollo del proceso conforme al art. 48 de su Estatuto, por ejemplo, para indicar medidas provisionales, para tomar nota del desistimiento de las partes en el procedimiento y ordenar la cancelación del asunto del registro general o para establecer los plazos para la presentación de la memoria y la contramemoria. De la misma forma, en la jurisdicción del CIADI los tribunales arbitrales también dictan toda una serie de decisiones a lo largo del procedimiento que son necesarias para el buen desarrollo del mismo, como son las resoluciones procesales (art. 44 del Convenio CIADI y Regla 19 de las Reglas de Arbitraje del CIADI) o las decisiones sobre medidas provisionales (art. 47 del Convenio CIADI y Regla 39 de las Reglas de Arbitraje del CIADI).

62 J.J. Quintana, Litigation at the International Court of Justice. Practice and Procedure, Leiden/Boston, Brill/Nijhoff, 2015, p. 523: "It may be noted that under Articles 59 y 60 of the Statute both decisions have the full force of res judicata, a point made by the Court in the Nicaragua case": ver Application of the Convention on the Prevention and Punishment of the Crime of Genocide (Bosnia and Herzegovina v. Serbia and Montenegro), Judgment, I.C.J. Reports 2007, párr. 117: "It has however been suggested by the Respondent that a distinction may be drawn between the application of the principle of res judicata to judgments given on the merits of a case, and judgments determining the Court's jurisdiction, in response to preliminary objections; specifically, the Respondent contends that "decisions on preliminary objections do not and cannot have the same consequences as decisions on the merits". The Court will however observe that the decision on questions of jurisdiction, pursuant to Article 36, paragraph 6, of the Statute, is given by a judgment, and Article 60 of the Statute provides that " $[\mathrm{t}]$ he judgment is final and without appeal", without distinguishing between judgments on jurisdiction and admissibility, and judgments on the merits. In its Judgment of 25 March 1999 on the request for interpretation of the Judgment of 11 June 1998 in the case of the Land and Maritime Boundary between Cameroon and Nigeria, the Court expressly recognized that the 1998 Judgment, given on a number of preliminary objections to jurisdiction and admissibility, constituted res judicata, so that the Court could not consider a submission inconsistent with that judgment (Judgment, I.C.J. Reports 1999 (I), p. 39, para. 16). Similarly, in its Judgment of 3 February 2003 in the Application for Revision case, the Court, when it began by examining whether the conditions for the opening of the revision procedure, laid down by Article 61 of the Statute, were satisfied, undoubtedly recognized that an application could be made for revision of a judgment on preliminary objections; this could in turn only derive from a recognition that such a judgment is "final and without appeal". Furthermore, the contention put forward by the Respondent would signify that 
ración, revisión y anulación se emplea el término "decisión", estas decisiones se deben equiparar a los laudos a efectos de su reconocimiento y ejecución, tal como establece el art. 53.2 del Convenio CIADI. ${ }^{63}$

36. El árbitro G. Abi-Saab, que ha actuado como juez ad hoc en diversos casos ante la CIJ, ${ }^{64}$ señaló esta particularidad del sistema CIADI en una opinión disidente en ConocoPhillips y otros c. Venezuela. Afirmó, en efecto, que las normas procesales de otros tribunales internacionales (entre ellos citaba la CIJ, la Corte Penal Internacional, el Tribunal Europeo de Derechos Humanos y otros sistemas arbitrales) establecían que las decisiones interlocutorias, particularmente sobre excepciones preliminares, e incluso decisiones parciales sobre cuestiones de fondo, se emitían en forma de sentencia o laudo y, por lo tanto, eran susceptibles de ser atacadas por cualquiera de los recursos que cada sistema previera para subsanar o modificar sentencias o laudos defectuosos, pero que esto no ocurría en el CIADI. ${ }^{65} \mathrm{El}$ efecto de cosa juzgada de este tipo de decisiones podía ser válido bajo el régimen del DI general, pero la normativa procesal del CIADI se consideraba lex specialis, que establecía que la cosa juzgada solo la podía producir el laudo que debe contener todas las decisiones anteriores, conforme al art. $48.3 \mathrm{del}$ Convenio CIADI, considerándolo como un "package deal". ${ }^{66}$

37. Asimismo, cuando en 2004 se propuso crear un mecanismo de apelación en el CIADI, se señaló que los tribunales constituidos conforme a la normativa del CIADI solo emitían una decisión definitiva, que era el laudo que resuelve la controversia. Las decisiones anteriores formaban parte del laudo y a partir de ese momento cabía solicitar su anulación o presentar cualquier otro recurso contra el laudo previsto en la normativa. Además, se señaló la diferencia con otras normas de procedimiento, como las Reglas de la CNUDMI. En los arbitrajes desarrollados conforme a estas últimas se dictan decisiones preliminares en forma de laudo parcial contra las que cabe impugnación inmediata e incluso se sugirió que, para evitar discrepancias entre los "casos CIADI" y los "casos ajenos al CIADI", las reglas de procedimiento del órgano de apelación deberían establecer si era posible o no impugnar las decisiones preliminares o los laudos parciales, ${ }^{67}$ lo que sin duda pondría fin a la problemática que aquí se estudia.

38. No obstante, el efecto de cosa juzgada de las decisiones preliminares en procedimientos bifurcados o trifurcados ${ }^{68}$ no ha sido una cuestión pacífica en la práctica arbitral, lo que nos sitúa en una

the principle of res judicata would not prevent a judgment dismissing a preliminary objection from remaining open to further challenge indefinitely, while a judgment upholding such an objection, and putting an end to the case, would in the nature of things be final and determinative as regards that specific case."

${ }_{63}$ Art. 53.2 del Convenio CIADI, "A los fines previstos en esta Sección, el término "laudo" incluirá cualquier decisión que aclare, revise o anule el laudo, según los Artículos 50, 51 o 52”.

${ }^{64}$ Différend frontalier (Burkina Faso/République du Mali), arrêt, C.I.J. Recueil 1986, p. 554; y, Différend territorial (Jamahiriya Arabe Libyenne/Tchad), arrêt, C.I.J. Recueil 1994, p. 6.

${ }_{65}$ Ver la opinión disidente de G. Abi-Saab en ConocoPhillips Petrozuata B.V. y otros c. Venezuela (Caso CIADI N ${ }^{\circ}$ ARB/07/30), Decisión sobre Reconsideración de 10 de marzo de 2014, párrs. 42 y 46.

${ }^{66} \mathrm{Ibid}$., párrs. 43-44: "It appears that the rationale or philosophy underlying this peculiarity of the ICSID procedural system is to have all the controverted issues of a case resolved in a kind of a package deal; probably to ensure that while deciding in law, a tribunal will have at the back of its mind the total balance of equities. Finality thus comes with the closure of this all inclusive package in the form of an instrument it calls "award"; and attaches to the whole as well as to its constitutive parts simultaneously; but only from that moment on. Until that moment, according to the inner logic of this chosen system or lex specialis, all the components of the package, whether decided upon or not, remain on the table (or the Bench), amenable to rectification and adjustment by the Tribunal, in order to fit better in, and to perfect as much as possible the final product, which is the package as a whole."

67 "An ICSID arbitral tribunal renders just one award, the final award disposing of the case. Earlier decisions of the tribunal will be deemed part of the award and subject at that stage to annulment and other post-award remedies. In some other systems of arbitration, including arbitration under the UNCITRAL Rules, interim decisions of the tribunal may be made in the form of awards and possibly challenged immediately. To avoid discrepancies of coverage between ICSID and non-ICSID cases, the Appeals Facility Rules might either provide that challenges could in no case be made before the rendition of the final award or allow challenges in all cases in respect of interim awards and decisions. (...)": ver ICSID Secretariat, Discussion Paper, Possible Improvements of the Framework for ICSID Arbitration, de 22 de octubre de 2004, Annex, párr. 8. Sobre la distinción entre decisiones y laudos: ver C. Tiтi, loc. cit., pp. 363-364 y 379.

${ }^{68}$ En los casos estudiados los procedimientos se han sustanciado en dos o incluso tres fases ("trifurcación"); una primera fase en la que se ha decidido sobre la jurisdicción y responsabilidad y/o derecho aplicable y, una segunda fase, sobre la cuan- 
situación de posible riesgo de fragmentación o inconsistencias en el DI de las inversiones, en la medida en que la discrepancia entre tribunales respecto a la interpretación o aplicación de una norma en casos en que se presentan situaciones fácticas o jurídicas análogas puede generar incertidumbre y falta de previsibilidad y, en definitiva, una pérdida de confianza de los sujetos en el sistema de arreglo de controversias.

39. Esta divergencia de opiniones se ha generado en procesos arbitrales en los que una de las partes ha solicitado al órgano arbitral que ejerciera una potestad de reconsideración de estas decisiones previas al laudo; decisiones que se pronunciaban sobre cuestiones de jurisdicción, pero también sobre responsabilidad. Por lo tanto, el debate sobre el efecto de cosa juzgada de las decisiones preliminares se encuentra ligado a una posible facultad de reconsideración de estas decisiones, pues la conclusión alcanzada por estos órganos arbitrales sobre la reapertura de una cuestión ya decidida en el marco del procedimiento ha dependido, en gran medida, de su interpretación del principio de cosa juzgada en relación con otras disposiciones del Convenio CIADI y de sus Reglas de Arbitraje. En las siguientes líneas se exponen y sistematizan los argumentos que han conducido a algunos tribunales arbitrales a mantener posiciones divergentes sobre esta cuestión.

\section{Las distintas aproximaciones al principio de cosa juzgada en la práctica arbitral}

\section{A) Una interpretación extensiva y generalista}

40. En primer lugar, abordamos dos casos en los que se ha considerado que las decisiones preliminares poseen efecto de cosa juzgada antes de incorporarse al laudo ${ }^{69}$ Por este motivo, consideramos que estos órganos arbitrales han realizado una interpretación extensiva del principio de cosa juzgada que no sólo afectaría al laudo que pone fin al procedimiento, sino también a las decisiones previas al laudo; y generalista, ya que esta aplicación del principio a las cuestiones decididas con carácter previo al laudo en procedimientos bifurcados, no responde a la particular distinción entre "decisión" y "laudo" en la normativa del CIADI, sino que parece inspirarse en la estructura del Estatuto de la CIJ, en que tanto las cuestiones de jurisdicción como de fondo se resuelven de manera definitiva por medio de fallo y, por ende, con efecto de cosa juzgada.

41. En uno de estos arbitrajes, ConocoPhillips c. Venezuela, se dictaron tres decisiones sobre reconsideración. ${ }^{70}$ En su primera Decisión sobre reconsideración, de 10 de marzo de 2014, el órgano arbitral dejó claro que el objetivo de su decisión sobre la solicitud de Venezuela era responder a la cuestión de si el tribunal tenía la facultad que pretendía la demandada, pero no entrar a examinar los argumentos alegados por ella ni la prueba en que se apoyaba; por lo tanto, el órgano arbitral se limitó a resolver so-

tificación de daños (quantum) junto con el laudo que incorpora todas las decisiones anteriores; cuando se ha trifurcado, se han separado las fases de jurisdicción, responsabilidad y, finalmente, cuantificación de daños.

${ }^{69}$ Perenco Ecuador Ltd. c. Ecuador y Petroecuador (Caso CIADI No ARB/08/6), Decisión sobre Reconsideración de 10 de abril de 2015; y ConocoPhillips Petrozuata B.V. y otros c. Venezuela (Caso CIADI No ARB/07/30). En este último arbitraje se dictaron tres decisiones sobre reconsideración: la Decisión sobre Reconsideración de 10 de marzo de 2014, la Decisión sobre Reconsideración 9 de febrero de 2016 y la Decisión preliminar (“Interim Decision”) de 17 de enero de 2017.

${ }^{70}$ La primera decisión, de 10 de marzo de 2014, resolvió sobre la reconsideración solicitada por Venezuela sobre determinadas cuestiones resueltas por medio de la Decisión sobre Jurisdicción y Fondo de 3 de septiembre de 2013, por la que el tribunal se declaró competente en virtud del art. 9 del APPRI celebrado entre Países Bajos y Venezuela (firmado el 22 de octubre de 1991) para conocer de determinadas reclamaciones de las empresas demandantes y, sobre las cuestiones de fondo, declaró que Venezuela había incumplido su obligación de negociar de buena fe a fin de determinar la compensación debida por la expropiación que había realizado de los activos de ConocoPhillips en tres proyectos, en función del valor de mercado, lo que suponía una violación de la obligación contenida en el art. 6.c) del citado APPRI (Decisión sobre Jurisdicción y Fondo de 3 de septiembre de 2013, párr. 404). La segunda decisión, de 9 de febrero de 2016, resolvió sobre la solicitud de reconsideración de la propia Decisión de 10 de marzo de 2014, que volvió a plantear Venezuela, habiendo sido rechazada la primera solicitud. La tercera Decisión sobre reconsideración se emitió el 17 de enero de 2017, bajo el nombre de "interim decision", que de nuevo planteó Venezuela sobre la Decisión de reconsideración de 2016 que fue también rechazada. Los motivos alegados por Venezuela en las tres peticiones fueron idénticos. 
bre la existencia de tal facultad. El tribunal estableció que las cuestiones resueltas por la decisión sobre jurisdicción y fondo poseían efecto de cosa juzgada bajo los siguientes argumentos: primero, aunque las disposiciones del art. 53 del Convenio CIADI y otras incluidas en la Sección 5 de su Capítulo IV (aclaración, revisión y anulación del laudo) no se podían aplicar directamente, ya que se referían al laudo que pone fin al procedimiento, no significaba que no fueran relevantes en un sentido más general $;{ }^{71}$ segundo, la decisión sobre jurisdicción y fondo que se pretendía reconsiderar no era una decisión "interina" o "preliminar" (como alegaba Venezuela) debido a la naturaleza de las cuestiones que resolvía, ya que eran cuestiones controvertidas y las decisiones que resolvían este tipo de cuestiones poseían efecto de cosa juzgada; en palabras del órgano arbitral:

"Según la práctica, estas decisiones deben incorporarse al Laudo. Tanto en teoría como en la práctica es aceptado que aquellas decisiones que resuelven cuestiones controvertidas entre las Partes tienen efecto de cosa juzgada. 'Son de naturaleza definitiva, y no pueden ser objeto de reconsideración por las Partes o por el Tribunal en ninguna etapa ulterior del arbitraje."”72

42. En la segunda Decisión de 9 de febrero de 2016, el órgano arbitral se centró principalmente en la inexistencia de una base jurídica que facultara al tribunal para reabrir las cuestiones ya decididas antes de finalizar el procedimiento por medio de laudo; como tampoco estimó que la ausencia de una disposición al respecto fuera una laguna procesal que pudiera subsanarse mediante un poder inherente o por aplicación analógica de alguna disposición de la normativa CIADI. ${ }^{73}$ De hecho, el tribunal se refirió a la reconsideración que solicitaba Venezuela como una "substantive reconsideration". ${ }^{74}$ Respecto a la cosa juzgada, confirmó lo establecido en la Decisión de 10 de marzo de 2014 aludiendo a jurisprudencia arbitral que, en alguna medida, apoyaba el carácter final y la imposibilidad de reabrir las cuestiones decididas durante el procedimiento. ${ }^{75}$ Asimismo, el tribunal se pronunció sobre la petición de reconsideración de la Decisión de 10 de marzo de 2014, advirtiendo que la propia Decisión sobre la reconsideración producía efecto de cosa juzgada y no se podía volver a examinar, ${ }^{76}$ lo que resulta coherente con su postura respecto a las decisiones que no constituyen un laudo.

43. En la tercera y última Decisión sobre la reconsideración solicitada por Venezuela, emitida el 17 de enero de 2017, el órgano arbitral no se pronunció sobre el efecto de cosa juzgada ni tampoco sobre la existencia de una facultad de reconsideración, aunque efectivamente entró a examinar los argumentos planteados, llegando a la conclusión de que no procedía modificar la Decisión original sobre jurisdicción y fondo de 2013. Podría pensarse que este modo de proceder indicaría un reconocimiento implícito de esta facultad y, por ende, del carácter meramente preliminar de la decisión. Pero del contenido de la decisión interpretamos que entró a valorar los argumentos únicamente para aclarar el sentido y alcance de uno de los pronunciamientos contenidos en la Decisión original de 2013 sobre el que todavía existía controversia entre las partes en esta fase del procedimiento. En cualquier caso, llama la atención este cambio en la manera de proceder del tribunal, ya que es ambiguo y genera incertidumbre sobre la posibilidad de reconsiderar estas decisiones. ${ }^{77}$ A tal efecto, es importante señalar que las decisiones de 2014 y 2016

${ }^{71}$ ConocoPhillips Petrozuata B.V. y otros c. Venezuela (Caso CIADI No ARB/07/30), Decisión sobre Reconsideración de 10 de marzo de 2014, párr. 19.

${ }_{72}$ Ibid., párr. 21. En apoyo de este argumento se cita en nota al pie el caso Electrabel S.A. c. Hungría (Caso CIADI N ${ }^{\circ}$ ARB/07/19), Decisión sobre Jurisdicción, Derecho aplicable y Responsabilidad de 30 de noviembre de 2012, ver nota 79.

${ }^{73}$ ConocoPhillips Petrozuata B.V. y otros c. Venezuela (Caso CIADI No ARB/07/30), Decisión sobre Reconsideración de 10 de marzo de 2014, párrs. 22-23; y ConocoPhillips Petrozuata B.V. y otros c. Venezuela (Caso CIADI No ARB/07/30), Decisión sobre Reconsideración de 9 de febrero de 2016, párrs. 23, 28, 36-37.

${ }^{74}$ ConocoPhillips Petrozuata B.V. y otros c. Venezuela (Caso CIADI No ARB/07/30), Decisión sobre Reconsideración de 9 de febrero de 2016, párr. 28

${ }^{75}$ Ibid., párrs. 31-38.

${ }^{76}$ Ibid., párr. 21.

${ }_{77}$ ConocoPhillips Petrozuata B.V. y otros c. Venezuela (Caso CIADI No ARB/07/30), Decisión Preliminar de 17 de enero de 2017, párrs. 61-62. En especial, el párr. 62 establece: “Therefore, the Respondent's Third Application for Reconsideration must be considered as moot to the extent it required the Tribunal to review an assessment of lack of good faith in negotiating for compensa- 
fueron adoptadas por mayoría, no por unanimidad, ya que los árbitros G. Abi-Saab y A. Bucher, emitieron opiniones disidentes, lo que demuestra, una vez más, que no estamos ante una cuestión pacífica.

44. El segundo caso en que un órgano arbitral ha decidido en favor de la cosa juzgada de las decisiones preliminares es Perenco Ecuador Ltd. c. Ecuador y Petroecuador (en adelante, Perenco c. Ecuador). Este órgano arbitral fue llamado a dirimir esta cuestión en un momento intermedio entre la primera y segunda decisión dictada en el caso ConocoPhillips Petrozuata B.V. y otros c. Venezuela. Así las cosas, no es de extrañar que el órgano arbitral en Perenco c. Ecuador dirigiese su mirada hacia la Decisión de 10 de marzo 2014 dictada en ConocoPhillips Petrozuata B.V. y otros c. Venezuela.

45. La decisión emitida en Perenco c. Ecuador es, sin duda, más extensa en cuanto a los argumentos utilizados por el tribunal para fundamentar sus conclusiones. No obstante, el órgano arbitral no profundizó en la cuestión del efecto de cosa juzgada de las decisiones anteriores al laudo, sino que examinó cada una de las disposiciones del Convenio CIADI y las Reglas de Arbitraje del CIADI invocadas por Ecuador como fundamento jurídico de la facultad de reconsideración, con el objetivo de demostrar que las mismas no eran aplicables a las decisiones previas al laudo.

46. Así, al examinar si el art. 51 del Convenio CIADI (relativo a la revisión) podía aplicarse a una decisión previa al laudo, el órgano arbitral afirmó que existía un amplio consenso sobre el efecto de cosa juzgada que protege a las cuestiones de hecho o de derecho resueltas por un tribunal, como era el caso de la Decisión sobre cuestiones pendientes relativas a la jurisdicción y responsabilidad de $12 \mathrm{de}$ septiembre de 2014, cuya reconsideración solicitaba Ecuador. ${ }^{78}$

47. El órgano arbitral fundamentó este "amplio consenso" en diversas decisiones arbitrales, algunas de las cuales también sirvieron de base al órgano arbitral en ConocoPhillips Petrozuata B.V. y otros $c$. Venezuela. Sin embargo, las decisiones allí mencionadas ${ }^{79}$ no responden exactamente al mismo

tion on the part of the Bolivarian Republic of Venezuela, which is not contained in the Tribunal's 2013 Decision. The Tribunal must dismiss the Application in this regard, irrespective of whether the Tribunal would have, or does not have the power to reconsider the Application (as decided twice by the Tribunal's Majority)." [La cursiva es nuestra] En el laudo final, que incorpora todas las decisiones preliminares, el tribunal señaló: "Sin embargo, el significado y los efectos verdaderos del extracto de la Decisión de 2013 con respecto al desarrollo de las negociaciones en materia de compensación por parte de la Demandada incluido en el párrafo 404(d) siguió siendo objeto de debate. El Tribunal consideró que sería de utilidad contar con mayor claridad en relación con la obligación que prohíbe la expropiación por parte del Estado receptor según se señala en el Artículo 6 del TBI y en relación con la evaluación de la reclamación de indemnización de daños planteada por de las Demandantes. (...)" [La cursiva es nuestra]: ver ConocoPhillips Petrozuata B.V. y otros c. Venezuela (Caso CIADI No ARB/07/30), Laudo de 8 de marzo de 2019, párr. 41.

${ }_{78}$ Perenco Ecuador Ltd. c. Ecuador y Petroecuador (Caso CIADI No ARB/08/6), Decisión sobre Reconsideración de 10 de abril de 2015, párr. 43: "Existe amplio consenso respecto de que una vez que un tribunal resuelve cualquiera de las cuestiones de hecho o de derecho sometidas a su consideración por las partes, como fue el caso en la Decisión sobre las Cuestiones Pendientes relativas a la Jurisdicción y sobre la Responsabilidad, su decisión tiene carácter de cosa juzgada."

${ }^{79}$ Waste Management Inc c. México (II) (Caso CIADI No ARB (AF)/00/3), Decisión sobre la objeción preliminar de México relativa al procedimiento previo de 26 de junio de 2002, párr. 45: “(...) En los casos en que la misma cuestión se plantea en el nivel de la competencia y del fondo, puede ser apropiado unir la cuestión de competencia al fondo. Pero cualquiera que sea la etapa del proceso en que se tome la decisión, una decisión sobre un punto determinado constituye res judicata entre las partes en relación con tal decisión si es una parte necesaria de la determinación y es abordada como tal por el tribunal."; Electrabel S.A. c. Hungría (Caso CIADI No ARB/07/19), Decisión sobre Jurisdicción, Derecho aplicable y Responsabilidad de 30 de noviembre de 2012, párr. 10.1: "This Decision is made in regard only to the first phase of these arbitration proceedings, relating to extant issues of jurisdiction and liability; and it is not made in regard to any issue of quantum (including interest). Although necessarily described as a "Decision" and not an "Award" under the ICSID Convention and ICSID Arbitration Rules, the several decisions and reasons contained in this Decision are intended by the Tribunal to be final and not to be revisited by the Parties or the Tribunal in any later phase of these arbitration proceedings."; CMS Gas Transmission c. Argentina (Caso CIADI $\mathrm{N}^{\circ} \mathrm{ARB} / 01 / 8$ ), Laudo de 12 de mayo de 2005, párr. 126: "También cabe señalar que, en relación con el fondo, el Demandado planteó igualmente determinados aspectos de jurisdicción que ya se habían tratado en la fase de jurisdicción en este caso, como el relativo al jus standi del Demandante. Estos aspectos se decidieron en esa etapa y no serán reexaminados en este Laudo."; Quiborax S.A., Non Metallic Minerals S.A. y Allan Fosk Kaplún c. Bolivia (Caso CIADI n ARB/06/2), Laudo de 16 de septiembre de 2015, párrs. 541: “(...) The jurisdictional phase concluded with the Decision on Jurisdiction, in which the Tribunal established that it had jurisdiction over the claims of Quiborax and NMM. The Tribunal finds that there is no reason that can 
supuesto planteado en las solicitudes de reconsideración o se ha considerado que su aplicación se limitaba al caso concreto y no podía extenderse de manera general.

48. En suma, la posición de algunos órganos arbitrales consistente en la aplicación del principio de cosa juzgada a las decisiones preliminares no respondería a las particularidades del sistema CIADI, sino que se inspiraría en la práctica de otros tribunales internacionales. Con arreglo al DI general, en efecto, las cuestiones de jurisdicción y fondo decididas por medio de fallo son definitivas y obligatorias. Esta posición permite que las cuestiones ya decididas no estén en constante debate durante el procedimiento, lo que dificultaría su avance y conllevaría su prolongación excesiva, hasta el punto de perjudicar la buena administración de justicia.

\section{B) Una aplicación restrictiva y particularista}

49. En segundo lugar, varios tribunales arbitrales han defendido en fechas más recientes que las decisiones anteriores al laudo o preliminares no poseen efecto de cosa juzgada y, por tanto, pueden ser objeto de reconsideración. ${ }^{80}$ Por ello, entendemos que realizan una aplicación, primero, restrictiva del principio de cosa juzgada que se limitaría al laudo conforme al art. 53 del Convenio CIADI y, segundo, particularista porque esta conclusión atiende a las características particulares del sistema CIADI.

50. Estos órganos arbitrales han basado sus conclusiones en los siguientes fundamentos. Primero, el art. 48.3 del Convenio CIADI requiere que todas las cuestiones decididas por el órgano arbitral formen parte integrante del laudo. Si la decisión anterior fuera cosa juzgada, este requisito sería redundante. ${ }^{81}$ Segundo, no hay recursos disponibles en la normativa CIADI contra estas decisiones, sino únicamente respecto del laudo (rectificación, decisión suplementaria, aclaración, revisión y anulación) ${ }^{82}$ Tercero, estas son obligatorias para las partes y no tienen efectos $a d$ extra. ${ }^{83} \mathrm{Y}$, cuarto, en estrecha relación con lo anterior, los Estados partes del Convenio CIADI tienen la obligación de reconocer el laudo como vinculante en virtud de su art. $54.1 \mathrm{y}$ este precepto solo se refiere a los laudos (art. 54.2 del Convenio CIADI), por lo que las decisiones anteriores no pueden producir consecuencias jurídicas fuera del proceso en que se dictan (no se pueden reconocer, ni ejecutar, ni ser impugnadas por medio de anulación). ${ }^{84}$ En conclusión, el principio de cosa juzgada afectaría a los laudos, pero no a las decisiones anteriores. ${ }^{85}$

justify reopening the jurisdictional issues at this stage, assuming this were at all possible. It therefore denies the Respondent's new jurisdictional objections."

${ }^{80}$ Tethyan Copper Company Pty Limited c. Pakistán (Caso CIADI No ARB/12/1), Laudo 12 de julio de 2019 (conviene señalar que la Decisión sobre Reconsideración no se encuentra publicada y nos basamos en la síntesis que realiza el tribunal en el laudo que la incorpora por referencia. En el mismo, no se especifica que el tribunal se pronunciara expresamente sobre el efecto de cosa juzgada, sino que concluyó que tenía la facultad de reconsiderar la Decisión sobre Jurisdicción y Responsabilidad aplicando la causa del art. 51 del Convenio CIADI, ver párr. 165 del Laudo); Burlington Resources, Inc. c. Ecuador (Caso CIADI N ${ }^{\circ}$ ARB/08/5), Decisión sobre Reconsideración y Laudo de 7 de febrero de 2017; y Standard Chartered Bank (Hong Kong) Limited c. Tanzania Electric Supply Company Limited (Caso CIADI No ARB/10/20), Laudo de 12 de septiembre de 2016, en el marco de este arbitraje, ver también la Decisión sobre anulación de 22 de agosto de 2018.

${ }^{81}$ Standard Chartered Bank (Hong Kong) Limited c. Tanzania Electric Supply Company Limited (Caso CIADI N ${ }^{\circ}$ ARB/10/20), Laudo de 12 de septiembre de 2016, párrs. 309 y 314; y Burlington Resources, Inc. c. Ecuador (Caso CIADI N ARB/08/5), Decisión sobre Reconsideración y Laudo de 7 de febrero de 2017, párr. 86.

82 Standard Chartered Bank (Hong Kong) Limited c. Tanzania Electric Supply Company Limited (Caso CIADI N ${ }^{\circ}$ ARB/10/20), Laudo de 12 de septiembre de 2016, párr. 309. En el mismo sentido, Burlington Resources, Inc. c. Ecuador (Caso CIADI No ARB/08/5), Decisión sobre Reconsideración y Laudo de 7 de febrero de 2017, párr. 87.

${ }^{83}$ Standard Chartered Bank (Hong Kong) Limited c. Tanzania Electric Supply Company Limited (Caso CIADI N ${ }^{\circ}$ ARB/10/20), Laudo de 12 de septiembre de 2016, párrs. 312-313.

${ }^{84}$ Burlington Resources, Inc. c. Ecuador (Caso CIADI N ARB/08/5), Decisión sobre Reconsideración y Laudo de 7 de febrero de 2017, párrs. 87-88. Argumentos similares se utilizaron en Standard Chartered Bank (Hong Kong) Limited c. Tanzania Electric Supply Company Limited (Caso CIADI No ARB/10/20), Laudo de 12 de septiembre de 2016, párr. 314.

${ }^{85}$ Burlington Resources, Inc. c. Ecuador (Caso CIADI No ARB/08/5), Decisión sobre Reconsideración y Laudo de 7 de febrero de 2017, párr. 89. A la misma conclusión se arribó en Standard Chartered Bank (Hong Kong) Limited c. Tanzania Electric Supply Company Limited (Caso CIADI No ARB/10/20), Laudo de 12 de septiembre de 2016, párr. 318. 
51. Conviene señalar que el órgano arbitral en Standard Chartered Bank (Hong Kong) Limited c. Tanzania Electric Supply Company Limited (en adelante, SCB c. TANESCO), puso de manifiesto que, aunque estas decisiones no poseían efecto de cosa juzgada, ello no significaba que no fueran obligatorias para las partes y para el tribunal. Su carácter obligatorio en el marco del procedimiento (efecto jurídico ad intra) marcaba la diferencia respecto al efecto de cosa juzgada que, en definitiva, produce consecuencias jurídicas en relación con otros procesos arbitrales (efecto jurídico ad extra). En palabras del tribunal:

"Decisions of tribunals are of course binding within the scope of the proceedings, but this does not make them res judicata. That is so with procedural orders and provisional measures as pointed out earlier. An essential feature of res judicata is that the judgment in question produces effects on the parties outside the proceedings in which it is granted. But decisions of tribunals only have effect within the proceedings until they have been incorporated into the final award." ${ }^{86}$

52. En Burlington Resources c. Ecuador, el órgano arbitral se apoyó en la decisión anterior y afirmó:

"El Tribunal coincide con el tribunal del caso $S C B$ c. Tanesco cuando afirma que una decisión anterior al laudo no tiene efecto de cosa juzgada, por razones esencialmente vinculadas a la estructura o arquitectura del Convenio CIADI. (...)

(...) En efecto, los tribunales CIADI no han dudado en concluir que las decisiones preliminares obligan tanto a las partes como al tribunal en el curso del procedimiento." ${ }^{\$ 7}$

53. En esta misma línea, el árbitro A. Bucher, en una opinión disidente dictada en el caso ConocoPhillips Petrozuata B.V. y otros c. Venezuela, analizado supra, recordó el efecto que producía la cosa juzgada ad extra del laudo, es decir, en relación con otros procesos arbitrales, un efecto que no producían las decisiones anteriores al mismo:

"The use of the terms res judicata is subject to questions. This concept applies to situations where the same claim decided between the same parties and based on the same cause of action is raised in a distinct or successive proceeding. This notion does not apply to decisions to be made before the same court or tribunal in the same proceeding." ${ }^{98}$

54. En suma, los órganos arbitrales en $S C B$ c. TANESCO y Burlington Resources c. Ecuador interpretaron que, conforme al art. 48.3 del Convenio CIADI, las decisiones sobre cuestiones de jurisdicción o fondo emitidas con anterioridad al laudo solo producían efecto de cosa juzgada a partir del momento en que se incorporaran al laudo. ${ }^{89}$ Esta posición respondería a la condición de lex specialis de la normativa procesal del CIADI, que distingue entre "decisión" y "laudo", como ya apuntó el árbitro G. Abi-Saab en ConocoPhillips y otros c. Venezuela. ${ }^{90}$

55. No obstante, aunque no posean fuerza de cosa juzgada, los tribunales han establecido que son vinculantes en el marco del procedimiento en curso, por lo que no están admitiendo que estas de-

${ }^{86}$ Standard Chartered Bank (Hong Kong) Limited c. Tanzania Electric Supply Company Limited (Caso CIADI N ${ }^{\circ}$ ARB/10/20), Laudo de 12 de septiembre de 2016, párr. 313.

87 Burlington Resources, Inc. c. Ecuador (Caso CIADI No ARB/08/5), Decisión sobre Reconsideración y Laudo de 7 de febrero de 2017, párrs. 86 y 90.

${ }^{88}$ ConocoPhillips Petrozuata B.V. y otros c. Venezuela (Caso CIADI No ARB/07/30), Decisión sobre Reconsideración de 9 de febrero de 2016, párr. 40.

${ }^{89}$ С H.H. Schreuer et al., op. cit., p. 535, párr. 70: "A preliminary decision on jurisdiction will uphold jurisdiction at least in some matters. Otherwise it would not be preliminary. It terminates the interim procedure described above (...) and opens the way to proceedings on the merits. Upon delivery of the award on the merits, the decision on jurisdiction becomes part of the final award especially for purposes of annulment and recognition. Art. 48(3) of the Convention, providing that the award shall deal with every question submitted to the tribunal and state the reasons upon which it is based, requires that a preliminary decision on jurisdiction should be reflected in the final award (...).”

${ }^{90}$ Ver supra, nota 66. 
cisiones se puedan cuestionar y revisar una y otra vez a lo largo del proceso. Esta última reflexión nos conduce a indagar acerca de la base jurídica que posee la facultad de reconsideración, así como sobre las causas que justificarían su ejercicio y sus límites.

\section{La reconsideración como herramienta que promueve la buena administración de justicia}

\section{Los recursos como garantía de justicia}

56. A pesar de la indudable importancia del principio de cosa juzgada para el buen funcionamiento de todo sistema jurídico, nacional o internacional, no se debe ignorar la posibilidad de que los jueces o tribunales erren en sus decisiones. Por ello, todo sistema jurídico debe contar con determinados mecanismos procesales que permitan subsanar posibles errores en la administración de justicia.

57. Los recursos o medios de impugnación son habituales en los ordenamientos jurídicos nacionales. Sin embargo, en el sistema internacional se consideran, en general, excepcionales, como consecuencia de sus particularidades, entre ellas, la ya señalada especial necesidad de poner fin a las controversias, así como la ausencia de una organización jerárquica entre tribunales. ${ }^{91}$

58. En particular, en la jurisdicción de la CIJ únicamente es posible solicitar la interpretación del fallo (art. 60 del Estatuto de la CIJ), que no puede considerarse un recurso pues no afecta a la validez del fallo ni altera o modifica su contenido, y la revisión (art. 61 del Estatuto de la CIJ) condicionada al descubrimiento de un hecho nuevo que habría sido decisivo para la decisión del tribunal, si se hubiera conocido antes de dictar el fallo. La solicitud de apertura de estos procedimientos posteriores al fallo supone inevitablemente la prolongación de la controversia hasta que se resuelvan los mismos, pero solo la revisión puede considerarse que afectaría a la cosa juzgada del fallo, pues si se estimara una solicitud de revisión, el órgano jurisdiccional podría modificar la conclusión a la que arribó en el proceso anterior.

59. Estos mecanismos procesales se pueden activar tanto respecto a fallos que resuelven el fondo de la controversia como a fallos en los que la CIJ se pronuncia sobre su competencia. De hecho, en el marco del caso relativo a la Aplicación de la Convención para la prevención y la sanción del delito de genocidio (Bosnia y Herzegovina c. Serbia y Montenegro), la entonces República Federativa de Yugoslavia planteó una solicitud de revisión del fallo sobre excepciones preliminares de 11 de julio de 1996, en virtud del art. 61 del Estatuto de la CIJ. ${ }^{92}$

60. Con estos procedimientos posteriores al fallo se busca encontrar un equilibrio entre la necesidad de poner fin a las controversias de manera pacífica y la justicia de las decisiones de los órganos jurisdiccionales. Solo logrando este equilibrio puede garantizarse que un sistema de justicia funcione correctamente, es decir, que los jueces y tribunales garanticen una buena administración de justicia.

61. La normativa CIADI prevé cinco mecanismos procesales que se interponen con posterioridad al laudo y que permitirían su modificación con mayor o menor alcance: la rectificación (art. 49.2 del Convenio CIADI y Regla 49 de las Reglas de Arbitraje), la decisión suplementaria (art. 49.2 del Convenio CIADI y Regla 49 de las Reglas de Arbitraje), la interpretación (art. 50 del Convenio CIADI y Reglas 50, 51 y 54 de las Reglas de Arbitraje), la revisión (art. 51 del Convenio CIADI y Reglas 50, 51 y 54 de las Reglas de Arbitraje) y la anulación (art. 52 del Convenio CIADI y Reglas 50, 52 y 54 de

\footnotetext{
${ }^{91}$ E. LaUterPacht, loc. cit., pp. 526-528.

${ }_{92}$ Demande en révision de l'arrêt du 11 juillet 1996 en l'affaire relative à l'Application de la convention pour la prévention et la répression du crime de génocide (Bosnia-Herzegovina c. Yugoslavie) exceptions préliminaires (Yugoslavie c. Bosnia Herzégovine), arrêt, C.I.J. Recueil 2003, p. 7.
} 
las Reglas de Arbitraje). Algunos de estos mecanismos encuentran paralelismo con los procedimientos previstos en la jurisdicción de la CIJ, mientras que otros de gran impacto sobre el laudo, como la anulación, no están previstos en la normativa de la CIJ.

62. Como se ha indicado, estos procedimientos se pueden iniciar una vez dictado el laudo, por lo tanto, no procede su aplicación directa a las decisiones preliminares. Tanto el Convenio CIADI como las Reglas de Arbitraje del CIADI guardan silencio sobre una posible facultad de los tribunales arbitrales para reconsiderar cuestiones que ya han sido resueltas por medio de decisiones preliminares.

\section{La reconsideración de una decisión preliminar: ¿un poder inherente en aras de una buena ad- ministración de justicia o una actuación ultra vires de los órganos arbitrales?}

\section{A) La reconsideración como poder inherente necesario para la buena administración de justicia}

63. El debate abierto en torno a la aplicación del principio de cosa juzgada a las decisiones preliminares o interlocutorias se encuentra ligado a la posibilidad de solicitar la "reconsideración" de tales decisiones. El propio término "reconsideración" nos indica que nos encontramos ante una suerte de recurso que permitiría al órgano arbitral modificar sustancialmente o revocar la decisión preliminar, aunque al tratarse de una vía procesal no prevista en la normativa del CIADI, no es posible determinar apriorísticamente su ámbito de aplicación, es decir, las causas, los límites o efectos de este recurso.

64. En Burlington Resources c. Ecuador, el órgano arbitral señaló en dos ocasiones la falta de claridad del Convenio CIADI y las Reglas de Arbitraje del CIADI a este respecto:

“(...) Una vez efectuadas estas distinciones, se advierte que el marco del CIADI guarda silencio en cuanto a la posibilidad de reabrir una decisión anterior al laudo. ${ }^{93}$

(...)

Además, dada la falta de claridad del Convenio y las Reglas de Arbitraje CIADI en cuanto a si un tribunal puede reconsiderar una decisión anterior al laudo, no se puede considerar ilegítimo que Ecuador haya presentado una Petición de Reconsideración. Finalmente, esa petición se oyó conjuntamente con la fase de cuantificación de daños y no demandó una fase separada." ${ }^{.94}$

65. Asimismo, en $S C B$ c. TANESCO, el órgano arbitral comenzó su análisis diciendo:

"The Tribunal begins by observing that there is nothing in either the ICSID Convention or the Arbitration Rules dealing explicitly with the question of reconsideration of a decision." ${ }^{.95}$

66. En los arbitrajes analizados donde se ha presentado una solicitud de reconsideración, los solicitantes se han servido de múltiples disposiciones contenidas en el Convenio CIADI y en las Reglas de Arbitraje del CIADI con el objetivo de encontrar por analogía una base jurídica que sustentara sus pretensiones. En efecto, se han invocado todas aquellas disposiciones que de alguna manera permitirían al órgano arbitral reabrir una cuestión o modificar un laudo. ${ }^{96}$

${ }^{93}$ Burlington Resources Inc. c. Ecuador (Caso CIADI n ${ }^{\circ}$ ARB/08/5), Decisión sobre Reconsideración y Laudo de 7 de febrero de 2017, párr. 84.

${ }^{94}$ Ibid., párr. 632.

95 Standard Chartered Bank (Hong Kong) Limited c. Tanzania Electric Supply Company Limited (Caso CIADI N ${ }^{\circ}$ $\mathrm{ARB} / 10 / 20$ ), Laudo de 12 de septiembre de 2016, párr. 307. En el mismo sentido, en el marco de este procedimiento, Decisión sobre anulación de 22 de agosto de 2018, párr. 150: "The Committee concurs with the Tribunal's reasoning that neither the ICSID Convention nor the ICSID Arbitration Rules explicitly allow or disallow reconsideration of jurisdictional decisions.”.

${ }_{96}$ Arts. 41.1, 43, 44, 49.1 y 2, 51, 52 del Convenio CIADI; y Reglas 19, 25 y 38.2 de las Reglas de Arbitraje. 
67. En este punto, conviene matizar que la normativa CIADI no guarda absoluto silencio sobre la reapertura de cuestiones de jurisdicción resueltas mediante decisión en un procedimiento bifurcado. ${ }^{97}$ Así, la Regla 41.1 de las Reglas de Arbitraje del CIADI establece que las excepciones a la jurisdicción se plantearán "lo antes posible" y al mismo tiempo indica el momento procesal oportuno, aunque permite su invocación en otro momento cuando "la parte no haya tenido conocimiento entonces de los hechos en los que se funda la excepción". ${ }^{98} \mathrm{El}$ apartado 2 de la Regla 41 también establece que "el Tribunal podrá considerar de oficio en cualquier estado del procedimiento, si la diferencia que se le ha sometido cae dentro de la jurisdicción del Centro y es de su propia competencia", ${ }^{99}$ que podría interpretarse como la falta de efecto de cosa juzgada de las decisiones sobre jurisdicción y su posible reconsideración. ${ }^{100} \mathrm{Sin}$ embargo, en los casos de reconsideración estudiados, no solo se cuestionan decisiones sobre jurisdicción, sino también decisiones sobre responsabilidad y derecho aplicable, por lo que entendemos que la Regla 41 de las Reglas de Arbitraje no sería aplicable, directamente, a todas estas decisiones.

68. Por otro lado, también existe la posibilidad de solicitar al órgano arbitral la reapertura del procedimiento, siempre antes de que se dicte el laudo, cuando se descubra una prueba decisiva o surja una necesidad de aclaración (Regla 38.2 de las Reglas de Arbitraje del CIADI). Esta posibilidad podría suponer una modificación de una decisión anterior y, por consiguiente, del laudo definitivo, pero está estrictamente circunscrita a la condición señalada que, en esencia, coincide con la causa de revisión del art. 51 del Convenio CIADI. No obstante, cada mecanismo se acciona en un momento procesal distinto, en concreto, la revisión se solicita siempre con posterioridad al momento en que se dicta el laudo. Esta posibilidad que ofrece la Regla 38.2 tampoco es aplicable directamente a los supuestos de reconsideración estudiados, pues en estos casos el procedimiento no se había declarado cerrado, sino que todavía quedaba por resolver la cuantificación de daños en una fase ulterior del procedimiento. ${ }^{101}$ A pesar de lo anterior, siempre a nuestro juicio, este precepto es indicativo de la importancia que posee la buena administración de justicia, que prevalecería sobre la rigidez de la norma procesal que ordena el cierre del procedimiento en un momento determinado.

\footnotetext{
${ }^{97}$ Sobre este particular interesa destacar el trabajo de L.M. Bohmer, donde indica también que la normativa del CIADI no guarda silencio absoluto sobre la finalidad de las decisiones interlocutorias citando la Regla 41.1 y 38.2 de las Reglas de Arbitraje del CIADI. Por lo tanto, esta autora afirma: "As a consequence, the Arbitration Rules do not explicitly exclude the possibility that further jurisdictional issues may be raised after a decision on jurisdiction has been rendered. (...) As a consequence, the ICSID Convention and the ICSID Arbitration Rules clearly do not confer extended finality to all interlocutory decisions on jurisdiction.”: ver L.M. BOHMER, loc. cit., p. 241. La misma autora marca previamente la diferencia entre una bifurcación del procedimiento en fase de jurisdicción y fondo prevista en el Convenio (art. 41.2 del Convenio CIADI) y otras formas de bifurcación, normalmente en fase de jurisdicción y responsabilidad, por un lado, y fase de cuantificación de daños, por otro.

${ }^{98}$ Regla 41.1 de las Reglas de Arbitraje: "Toda excepción que la diferencia o una demanda subordinada no cae dentro de la jurisdicción del Centro o que por otras razones no es de la competencia del Tribunal, deberá oponerse lo antes posible. La parte que oponga la excepción deberá presentársela al Secretario General a más tardar antes del vencimiento del plazo fijado para la presentación del memorial de contestación o, si la excepción se refiere a una demanda subordinada, para la presentación de la réplica, a menos que la parte no haya tenido conocimiento entonces de los hechos en los que se funda la excepción."

${ }^{99}$ La cursiva es nuestra.

${ }^{100}$ Véanse, sobre la interpretación de la Regla 41.2 de las Reglas de Arbitraje y la facultad de reconsideración, los argumentos de las partes en Standard Chartered Bank (Hong Kong) Limited c. Tanzania Electric Supply Company Limited (Caso CIADI No ARB/10/20), Decisión sobre anulación de 22 de agosto de 2018, párrs. 110-149. Interesa, especialmente, el arbitraje Pac Rim Cayman LLC c. El Salvador (Caso CIADI No ARB/09/12), Laudo de 14 de octubre de 2016, en el que el tribunal afirmó: "En este sentido, en virtud del artículo 41(1) del Convenio CIADI y de la Regla 41(2) de las Reglas de Arbitraje del CIADI, este Tribunal tiene el deber, el derecho y la competencia para determinar el cumplimiento de los requisitos jurisdiccionales, sin importar la fase específica del arbitraje”, párr. 5.34. Por tanto, el tribunal reconoció que tenía facultad para reconsiderar su Decisión sobre Jurisdicción, pero también manifestó el debate existente en torno al efecto de cosa juzgada o no de las decisiones preliminares, por lo que prefirió no referirse a este principio; ver, en especial, párrs. 5.33-5.39.

${ }^{101}$ Algunos arbitrajes de interés para la práctica española en los que se ha invocado la Regla 38.2 son Antin Infrastructure Services Luxembourg S.à r.l. y Antin Energia Termosolar B.V. c. España (Caso CIADI No ARB/13/31), Laudo de 15 de junio de 2018, párrs. 56-58; y Masdar Solar \& Wind Cooperatief U.A. c. España (Caso CIADI No ARB/14/1), Laudo de 16 de mayo de 2018, párrs. 669-683. En estos casos, España solicitó la reapertura del procedimiento presentando como medio de prueba nuevo la STJUE (Gran Sala) 6 de marzo de 2018, República Eslovaca y Achmea B.V., C-284/16, EU:C:2018:158. En el caso Antin c. España, el Estado demandado también aportó una Decisión de la Comisión Europea sobre las ayudas de Estado: ver European Commission, State aid SA.40348 (2015/NN) - Spain Support for electricity generation from renewable energy sources, cogeneration and waste (C (2017) 7384 final), de 11 de noviembre de 2017.
} 
69. El precepto cuya invocación ha generado más dudas sobre su contenido y su adecuada interpretación ha sido el art. 44 del Convenio CIADI, contenido en la Sección 3 del Capítulo IV del Convenio CIADI ("Facultades y Funciones del Tribunal"), ${ }^{102}$ en relación con la Regla 19 de las Reglas de Arbitraje del CIADI. ${ }^{103}$

70. El art. 44 del Convenio CIADI faculta al órgano arbitral para resolver cualquier cuestión de procedimiento no prevista en la Sección 3 del Capítulo IV del Convenio CIADI, en las Reglas de Arbitraje del CIADI o en otras reglas acordadas por las partes. En concreto, este precepto establece in fine que: "Cualquier cuestión de procedimiento no prevista en esta Sección, en las Reglas de Arbitraje o en las demás reglas acordadas por las partes, será resuelta por el Tribunal." A este respecto, Ch.H. Schreuer indica: "An ICSID tribunal's power to close gaps in the rules of procedure is declaratory of the inherent power of any tribunal to resolve procedural questions in the event of lacunae" ${ }^{104}$

71. La facultad prevista en el art. 44 del Convenio CIADI, que se completa con la Regla 19 de las Reglas de Arbitraje, ha sido corroborada por la práctica arbitral como una facultad necesaria de los tribunales arbitrales. ${ }^{105}$ Los jueces y árbitros necesitan contar con cierto margen de discrecionalidad para llevar a cabo sus funciones, lo que implica poder colmar lagunas en la normativa procesal y resolver con celeridad y eficacia los problemas que surjan durante el procedimiento, ${ }^{106}$ todo ello en consonancia con el principio de economía procesal. ${ }^{107}$ Por eso, que los órganos arbitrales o judiciales gocen de unos poderes inherentes para llevar a cabo sus funciones no es discutible; ahora bien, la cuestión primordial a dilucidar es cuál es el contenido concreto de esos poderes inherentes o cuáles son sus límites. ${ }^{108}$

72. En todo caso, los tribunales no solo deben tener en cuenta principios de eficacia y economía procesal, sino procurar dictar decisiones justas. El objetivo de cualquier recurso o medio de impugnación contra una sentencia o laudo es evitar que un error cometido en un proceso genere una situación injusta que perviva en el tiempo. El grave perjuicio que la pervivencia de una injusticia provoca para los sujetos que han sometido su controversia a una determinada jurisdicción y para la credibilidad y legitimidad del sistema de justicia en general, justifica que se reflexione sobre la cuestión surgida en el seno del CIADI relativa a la "reconsideración" como una facultad encaminada a la buena administración de justicia.

73. Teniendo en cuenta todos los principios e intereses en presencia, los tribunales arbitrales se encuentran divididos en torno a esta facultad.

102 Por ejemplo, en ConocoPhillips Petrozuata B.V. y otros c. Venezuela (Caso CIADI No ARB/07/30), Decisión sobre Reconsideración de 10 de marzo de 2014, párr. 12, Venezuela alegó que “(...) un tribunal que aún se encuentra sesionando puede revisar sus decisiones "provisionales" y "preliminares". Considera que la Decisión es una decisión interlocutoria que ha sido emitida mucho antes del cierre del procedimiento. La Demandada alega que, de conformidad con el Artículo 44 del Convenio, el Tribunal conserva la facultad de examinar pruebas hasta el momento de la emisión del laudo."

${ }^{103}$ Regla 19 de las Reglas de Arbitraje del CIADI: "El Tribunal dictará las resoluciones necesarias para la sustanciación del proceso."

${ }^{104}$ Ch.H. SCHReuer et al., op. cit., p. 688, párr. 54.

${ }_{105}$ Churchill Mining PLC y Planet Mining Pty Ltd c. Indonesia (Casos CIADI No ARB/12/14 y 12/40), Resolución Procesal No 13 de 18 de noviembre de 2014, párr. 20; y Abaclat y otros c. Argentina (Caso CIADI No ARB/07/5), Decisión sobre Jurisdicción y Admisibilidad de 4 de agosto de 2011, párr. 521.

${ }^{106}$ R. KolB, loc. cit., párr. 25: "The principle or maxim of the 'proper administration of justice' has also helped the Court, when necessary, to invoke an inherent power to fill some gaps in the rules applicable to its procedure. (...)"; yer la opinión disidente de G. Abi-Saab en ConocoPhillips Petrozuata B.V. y otros c. Venezuela (Caso CIADI No ARB/07/30), Decisión sobre Reconsideración de 10 de marzo de 2014, párr. 54: "Article 44 is examined by the Majority, however, in the context of establishing whether or not the Tribunal has a general power of reconsideration. But this article is relevant in casu in another meaningful way, as a partial codification and specific application of the inherent jurisdiction or powers of any judicial or adjudicative organ."

${ }^{107}$ R. KolB, loc. cit., párr. 24, apdo. 5: "A proceeding is proper if, while taking account of the needs of expression of the parties, it remains short and non-cumbersome."

${ }_{108}$ El Juez Cançado Trindade expone algunos ejemplos de ejercicio del poder inherente de la CIJ: ver la opinión separada del Juez Cançado Trindade a la Providencia dictada por la CIJ el 17 de abril de 2013, párrs. 10-12. 
74. En SCB C. TANESCO, el demandante solicitó la reconsideración de la Decisión sobre jurisdicción y responsabilidad de 12 febrero de 2014. El tribunal arbitral reconoció que no existía una potestad específica para poder reconsiderar este tipo de decisiones, por lo que se centró en averiguar si, en ausencia de esta previsión, podía justificar esta acción a partir de los poderes más generales que confieren, por un lado, art. 41.1 del Convenio CIADI, que atribuye al tribunal arbitral la potestad para decidir sobre su propia competencia; ${ }^{109}$ y, por otro lado, el art. 44 del Convenio CIADI, ya citado.

75. El tribunal concluyó que, en virtud de su potestad de decidir sobre su propia competencia, podía reconsiderar una decisión preliminar $\mathrm{y}$, de hecho, procedió a su reconsideración. ${ }^{110}$ Asimismo, defendió este poder inherente por razones pragmáticas, en particular, sostuvo que mediante la reconsideración se evitaría que el tribunal decidiera sobre el fondo del asunto basándose en una decisión previa seriamente cuestionada. En caso de no poder reabrir la decisión en cuestión, los interesados tendrían que esperar a que se dictara el laudo definitivo para poder solicitar su revisión o anulación y es evidente que ello conllevaría un mayor tiempo y coste para las partes. Por esta razón, el tribunal concluyó que: "Efficiency grounds alone suggest that there may be circumstances where a tribunal should consider reopening a decision that it has made". ${ }^{111}$ Este pronunciamiento fue compartido por el órgano arbitral en Burlington Resources c. Ecuador, ${ }^{112}$ quien, tras repetir las palabras del tribunal en SCB c. TANESCO, añadió:

“(...) la eficacia procesal, que exige que una decisión provisional sea vinculante para el tribunal que ha emitido una decisión de tal naturaleza puede, al mismo tiempo, requerir una excepción al principio de fuerza vinculante en determinadas circunstancias. El Tribunal coincide con esta opinión." 113

76. Asimismo, el laudo emitido en $S C B$ c. TANESCO fue objeto de un recurso de anulación presentado por TANESCO, alegando una "extralimitación manifiesta de las facultades del tribunal" (art. 52.1.b del Convenio CIADI $)^{114}$ y "quebrantamiento grave de una norma de procedimiento" (art. $52.1 \mathrm{~d}$ ) del Convenio CIADI) ${ }^{115}$ en relación con la reconsideración, entre otros motivos. Este es un riesgo que ya apuntamos supra y que se corre cuando un tribunal ejerce una potestad no conferida expresamente en la normativa procesal aplicable. A título preliminar, el Comité ad hoc confirmó la posición del tribunal sobre la facultad de reconsideración en virtud de los arts. 41.1 y 44 del Convenio CIADI y la Regla 41.1 y 2 de las Reglas de Arbitraje. ${ }^{116}$ Posteriormente, entró a valorar las causales de anulación invocadas y

\footnotetext{
${ }^{109}$ Art. 41.1 del Convenio CIADI, "El Tribunal resolverá sobre su propia competencia.” Este precepto recoge el principio procesal Kompetenz-Kompetenz.

${ }^{110}$ Por tanto, el tribunal no solo basó su afirmación sobre la posibilidad de reconsiderar su decisión previa en el art. 44 del Convenio CIADI, sino en la facultad más amplia que le confiere el art. 41.1 del Convenio CIADI. Ver Standard Chartered Bank (Hong Kong) Limited c. Tanzania Electric Supply Company Limited (Caso CIADI No ARB/10/20), Laudo de 12 de septiembre de 2016, párr. 320. En el mismo sentido, en el marco de este arbitraje, ver Decisión sobre anulación de 22 de agosto de 2018, párrs. 152-153. En el párr. 153, el Comité de anulación señaló sobre el aptdo. 2 de la Regla 41 de las Reglas de Arbitraje: "The Committee finds that the clear wording of ICSID Arbitration Rule 41 (2), allowing a tribunal to consider jurisdictional objections "at any stage of the proceedings", i.e. including after having already rendered an interlocutory decision on jurisdiction, implies that such earlier findings on jurisdiction are subject to reconsideration."

111 Standard Chartered Bank (Hong Kong) Limited c. Tanzania Electric Supply Company Limited (Caso CIADI N ${ }^{\circ}$ ARB/10/20), Laudo de 12 de septiembre de 2016, párrs. 319-320.

112 Burlington Resources, Inc. c. Ecuador (Caso CIADI No ARB/08/5), Decisión sobre Reconsideración y Laudo de 7 de febrero de 2017, párr. 93.

113 Standard Chartered Bank (Hong Kong) Limited c. Tanzania Electric Supply Company Limited (Caso CIADI N ${ }^{\circ}$ ARB/10/20), Laudo de 12 de septiembre de 2016, párr. 93.

${ }^{114}$ TANESCO alegó que, al reconsiderar la decisión preliminar, el tribunal desconoció el efecto de cosa juzgada de la Decisión y la disposición contenida en el art. 53.1 del Convenio CIADI y decidió reconsiderar su decisión ignorando precedentes sólidos a este respecto. Standard Chartered Bank (Hong Kong) Limited c. Tanzania Electric Supply Company Limited (Caso CIADI No ARB/10/20), Decisión sobre anulación de 22 de agosto de 2018, párrs. 304-309.

${ }^{115}$ TANESCO alegó que el tribunal desconoció el carácter vinculante y el efecto de cosa juzgada de la decisión preliminar, lo que implicaba, a su vez, una violación del principio del debido proceso. Ibid. párrs. 359-370. Asimismo, alegó que el tribunal había aceptado argumentos de SCB HK sin darle la oportunidad a TANESCO de responder o aportar prueba, párrs. 393-407.

${ }^{116}$ Ibid. párrs. 158, 159 y 169.
} 
rechazó la solicitud de TANESCO. ${ }^{117} \mathrm{El}$ hecho de que el Comité, formado por miembros distintos al tribunal de origen, haya ratificado la decisión adoptada por el tribunal supone un precedente más a favor de la facultad de reconsideración de las decisiones preliminares como un poder inherente de los tribunales.

\section{B) La reconsideración como ejercicio ultra vires de las facultades del órgano arbitral}

77. Cuando los órganos arbitrales han negado la existencia de una facultad de reconsiderar, como es en ConocoPhillips y otros c. Venezuela, el tribunal defendió un alcance limitado del art. 44 del Convenio CIADI, es decir, este tribunal entendió que reconsiderar una decisión anterior excedía los límites establecidos por el marco normativo del CIADI y tampoco lo habían previsto las partes por medio de acuerdo:

“(...) Con frecuencia se sostiene que el objeto del Artículo 44 es el de permitir que se subsanen lagunas procesales. No se le puede interpretar de modo tal de conferir una amplia facultad de decisión sustantiva no explícitamente otorgada." 118

78. El tribunal presentó ejemplos de "cuestiones procesales" resueltas en virtud del art. 44 del Convenio CIADI extraídas de decisiones arbitrales previas, como límites temporales, producción de documentos, suspensión del procedimiento estando otro arbitraje pendiente, autorización para presentar amicus curiae o sobre la participación de los representantes legales. ${ }^{119}$ En virtud de esta práctica, concluyó que la aplicación de este precepto no se extendía a una "facultad de decisión sustantiva no expresamente otorgada". ${ }^{120}$ Asimismo, en su segunda Decisión sobre reconsideración emitida en el marco del mismo procedimiento, se reafirmó en el carácter procesal de esta disposición aludiendo a los trabajos preparatorios del Convenio CIADI, a la doctrina y a los precedentes donde ya se había aplicado a cuestiones procesales como las mencionadas. ${ }^{121}$

79. En Perenco Ecuador c. Ecuador el órgano arbitral, tras descartar la aplicación de la normativa CIADI para modificar un laudo al tipo de solicitud que planteaba Ecuador, rechazó que la falta de una potestad en la normativa en el CIADI para reabrir una decisión fuera una laguna procesal que debiera subsanarse. ${ }^{122}$ Además, señaló:

"El Artículo 44 del Convenio no dispone una facultad general de reconsideración de la decisión del tribunal. Por último, no existe fundamento para invocar las facultades propias del Tribunal, ya que dichas facultades no pueden prevalecer sobre el texto llano del Convenio y de las Reglas de Arbitraje cuando se trata de modificar o reabrir un laudo." ${ }^{23}$

80. Por lo tanto, en estos dos casos la facultad de reabrir y modificar una decisión preliminar excedería los límites de la facultad inherente reconocida a los órganos arbitrales en el art. 44 del Convenio CIADI.

117 Ibid. párrs. 316-330 y 385-392 en relación con párrs. 437-449.

${ }_{118}$ ConocoPhillips Petrozuata B.V. y otros c. Venezuela (Caso CIADI No ARB/07/30), Decisión sobre Reconsideración de 10 de marzo de 2014, párr. 22.

119 Estos ejemplos coinciden con los presentados en el Comentario de referencia del Convenio CIADI: ver CH.H. SCHREUER et al., op. cit., pp. 689-690, párrs. 56-58.

${ }^{120}$ ConocoPhillips Petrozuata B.V. y otros c. Venezuela (Caso CIADI No ARB/07/30), Decisión sobre Reconsideración de 10 de marzo de 2014, párr. 22.

${ }^{121}$ ConocoPhillips Petrozuata B.V. y otros c. Venezuela (Caso CIADI No ARB/07/30), Decisión sobre Reconsideración de 9 de febrero de 2016, párrs. 23-25.

${ }^{122}$ Perenco Ecuador Ltd. c. Ecuador y Petroecuador (Caso CIADI No ARB/08/6), Decisión sobre Reconsideración de 10 de abril de 2015, párrs. 77 y 78 .

${ }^{123}$ Ibid., párr. 97. 
81. Ch. Brown señala como uno de los posibles límites a los poderes inherentes de un tribunal, el hecho de que el poder que se pretenda ejercer no esté previsto en la normativa y sea contrario a los procedimientos que, en cambio, sí prevé la normativa. ${ }^{124}$ Algunas partes en estos casos ante el CIADI han defendido este límite a la hora de valorar si una determinada medida del órgano arbitral estaba justificada o iba más allá de sus facultades necesarias para ejercer su función. En RSM Production Corporation c. Granada, por ejemplo, el tribunal declaró:

"The Committee agrees with the Applicant that international courts and tribunals have certain inherent powers which permit them to exercise powers that may go beyond the express terms of their constitutive instruments. However, the Committee considers that international courts and tribunals can only exercise such powers where those powers are necessary to ensure the performance of functions that have been expressly conferred. Further, there are limitations on the exercise of inherent powers, including that such powers cannot be inconsistent with the terms of the relevant constitutive instrument of the international court or tribunal." 125

82. Entendemos que, en ambos casos, los órganos arbitrales encontraron los límites a la solicitud de reconsideración tanto en los términos del Convenio CIADI y sus Reglas de Arbitraje como en la propia estructura de este sistema. En la primera Decisión sobre reconsideración de 2014, en ConocoPhillips y otros c. Venezuela, el tribunal declaró:

"La estructura general y las normas detalladas del Convenio del CIADI fueron diseñadas claramente para permitir la revisión o recursos respecto de las decisiones de un tribunal solo después del dictado del Laudo. No hay ninguna laguna que se pueda subsanar mediante la facultad que aquí se propone. (...)”26

83. Ciertamente, cuando la norma no prevé una determinada acción, es decir, cuando no permite, pero tampoco prohíbe su ejercicio, es difícil determinar apriorísticamente si dicha acción está legitimada ${ }^{127}$ A nuestro juicio, es necesario examinar el conjunto de disposiciones contenidas en la norma, su objetivo y finalidad, para poder inferir si la acción estaría legitimada.

84. El caso Abaclat y otros c. Argentina ${ }^{128}$ resulta interesante en la medida en que el órgano arbitral tuvo que valorar si la ausencia en la normativa del CIADI de una disposición que permitiera las demandas colectivas debía considerarse como un "silencio cualificado", es decir, si el silencio normativo había sido intencionado y, por lo tanto, este tipo de acciones no estaban permitidas o se trataba de una laguna procesal que el tribunal podía resolver. ${ }^{129} \mathrm{El}$ tribunal concluyó que no se trataba de un silencio

${ }^{124}$ Сн. Brown, loc. cit., p. 240: "A related type of limitation can be found where the constitutive instrument does not expressly exclude the exercise of a certain procedural power, but where the exercise of that power would nonetheless be inconsistent with the procedures actually provided for in the constitutive instrument or rules. (...)". En este sentido, СH.H. SCHREUER et al., op. cit., p. 688-689, párr. 54: "An ICSID tribunal's power to close gaps in the rules of procedure is declaratory of the inherent power of any tribunal to resolve procedural questions in the event of lacunae. In exercising this power, the tribunal may not go beyond the framework of the Convention, the Arbitration Rules and the parties' procedural agreements but, must, primarily, to attempt to close any apparent gaps through the established methods of interpretation for treaties and other legal documents." [Se omiten notas al pie].

${ }^{125}$ RSM Production Corporation c. Granada (Caso CIADI No ARB/05/14), Decisión de 7 de diciembre de 2009, párr. 20.

${ }^{126}$ ConocoPhillips Petrozuata B.V. y otros c. Venezuela (Caso CIADI No ARB/07/30), Decisión sobre Reconsideración de 10 de marzo de 2014, párr. 23.

127 Standard Chartered Bank (Hong Kong) Limited c. Tanzania Electric Supply Company Limited (Caso CIADI N ${ }^{\circ}$ ARB/10/20), Laudo de 12 de septiembre de 2016, párr. 315: "In the absence of any prohibition in the Convention or the Arbitration Rules on the question of reopening decisions, in the view of the Tribunal, it is not possible to draw any conclusions $a$ priori about the question of reopening."

${ }_{128}$ Abaclat y otros c. Argentina (Caso CIADI No ARB/07/5), Decisión sobre Jurisdicción y Admisibilidad de 4 de agosto de 2011, citado en la opinión disidente del árbitro A. Bucher, en ConocoPhillips Petrozuata B.V. y otros c. Venezuela (Caso CIADI N ${ }^{\circ} \mathrm{ARB} / 07 / 30$ ), Decisión sobre Reconsideración de 9 de febrero de 2016, párr. 45. El tribunal debía pronunciarse sobre el procedimiento colectivo como posible forma de arbitraje en el marco del CIADI.

${ }^{129}$ F. Pascual-Vives, La legitimación activa del individuo en el arbitraje de inversión, Pamplona, Aranzadi, 2019, pp. 168-174. 
cualificado y, por ende, tenía, en principio, la facultad conferida en virtud del art. 44 del Convenio del CIADI para solucionar esta laguna. ${ }^{130}$

85. Aplicando este razonamiento a la facultad de reconsideración que se cuestiona, se debe valorar, como hizo el tribunal en Abaclat c. Argentina, que dicho silencio normativo no fue intencionado. Para ello, en atención a las normas sobre la interpretación de los tratados internacionales, ${ }^{131}$ es necesario examinar la finalidad y objeto del Convenio CIADI, su art. 44 a la luz de otras disposiciones de la normativa CIADI, así como los trabajos preparatorios del Convenio CIADI y las Reglas de Arbitraje. Entendemos que es así como procedió el tribunal en ConocoPhillips y otros c. Venezuela y que le llevó a la conclusión de que el poder conferido por el art. 44 del Convenio CIADI al órgano arbitral no tenía por propósito resolver cuestiones sustantivas o de gran importancia. ${ }^{132}$ Además, tras exponer los recursos previstos en la normativa del CIADI contra los laudos, el tribunal afirmó:

"Nowhere is there any suggestion that the Tribunal might be able, before completing the award which may then be subject to that range of processes explicitly provided for in careful detail, to reexamine parts of its decision in effect by way of a rehearing or an appeal."133

86. Un razonamiento análogo se observa en un arbitraje interestatal que interesa traer a colación en este momento, dado que su reglamento de procedimiento se inspiró en la normativa CIADI. En efecto, en el caso de las Tasas a los Usuarios del Aeropuerto de Heathrow (Estados Unidos/Reino Unido), los Estados Unidos presentaron una solicitud de corrección, aclaración y decisión suplementaria del Laudo sobre responsabilidad. El tribunal reconoció que poseía un poder inherente para corregir errores de escritura, aritméticos y similares, pero para determinar si podía revisar el laudo más allá de este tipo de corrección, debía atenerse a la intención de las partes y, en virtud del carácter consensual que caracteriza al arbitraje, no podía ejercer una facultad que fuera contraria a lo acordado por ellas. Finalmente, tras analizar las disposiciones del Reglamento de procedimiento, concluyó que no tenía poderes inherentes para atender la solicitud de los Estados Unidos, pues la misma tenía una finalidad semejante a la apelación. ${ }^{134}$

87. Por lo tanto, estos casos muestran que los poderes inherentes que un tribunal puede ejercer se verían limitados por las normas constitutivas del órgano arbitral y otras normas procesales que pudiera haber aprobado o acordado las partes y, en definitiva, a la intención de sus redactores. Es evidente que, ante el silencio en la norma respecto a una acción concreta, las interpretaciones e inferencias que se extraigan pueden ser distintas, lo que supone un riesgo para la coherencia en las decisiones arbitrales.

\section{C) La reconsideración como un poder limitado para garantizar la eficacia del proceso y la correc- ción del laudo}

88. El planteamiento de un recurso que pueda alterar una cuestión ya decidida pone en riesgo la estabilidad de las relaciones jurídicas. Si las decisiones preliminares pudieran reabrirse en cualquier momento y en cualquier circunstancia, este hecho no solo generaría incertidumbre para los interesados y la imposibilidad de disfrutar plenamente de la situación declarada por el órgano jurisdiccional, sino que impediría avanzar en el proceso hacia su conclusión.

\footnotetext{
${ }_{130}$ Abaclat y otros c. Argentina (Caso CIADI No ARB/07/5), Decisión sobre Jurisdicción y Admisibilidad de 4 de agosto de 2011, párrs. 518-520.

${ }^{131}$ Convenio de Viena sobre el Derecho de los Tratados, de 23 de mayo de 1969, arts. 31-33.

${ }^{132}$ ConocoPhillips Petrozuata B.V. y otros c. Venezuela (Caso CIADI No ARB/07/30), Decisión sobre Reconsideración de 9 de febrero de 2016, párrs. 24-25.

${ }^{133}$ Ibid., párr. 27.

${ }^{134}$ United States-United Kingdom Arbitration concerning Heathrow Airport User Charges (United States-United Kingdom), 30 November 1992-2 May 1994. Decision No. 23 of the Tribunal (Supplementary Decisions and Clarifications) (Determination of USG's Request), Decisión de 1 de noviembre de 1993, UNRIAA, vol. XXIV, pp. 337-355, párrs. 2.30-2.32.
} 
89. En aras de preservar los intereses de los litigantes y la seguridad jurídica en general, los recursos suelen estar limitados por unas condiciones tasadas. La apelación es el recurso que impone unas condiciones menos rigurosas para su planteamiento y de ahí que sea el recurso ordinario por excelencia en los sistemas jurisdiccionales nacionales. La jurisdicción del CIADI no admite la apelación, tal como dispone expresamente el art. 53 del Convenio CIADI. Los restantes recursos, ya mencionados supra, están condicionados al cumplimiento de unos requisitos exigentes y que los órganos arbitrales se han ocupado de aclarar en la práctica.

90. En los casos más recientes los órganos arbitrales del CIADI han llegado a la conclusión de que podían reconsiderar una decisión previa emitida durante el procedimiento, pero han declarado que se trata de un poder limitado, por lo que únicamente se podrá reconsiderar una decisión anterior al laudo cuando concurran circunstancias excepcionales y limitadas ${ }^{135}$ puesto que, como afirmó el tribunal en $S C B$ c. TANESCO: "A decision of an ICSID tribunal cannot be considered to be merely a draft that can be reopened at will." 136

91. Tanto en $S C B$ c. TANESCO como en Burlington Resources c. Ecuador, los tribunales afirmaron que este poder de reconsideración debía guiarse, pero no estar sujeto, por los límites previstos en la normativa del CIADI para el reexamen de los laudos. ${ }^{137}$ En otras palabras, entendieron que reabrir una cuestión ya decidida debía estar sujeta a ciertos límites porque las decisiones anteriores eran de obligado cumplimiento; de lo contrario, una facultad ilimitada generaría una "incertidumbre considerable". ${ }^{138}$

92. En primer lugar, en $S C B$ c. TANESCO el tribunal declaró: "Whatever the power the tribunal has to reconsider a decision that power must at least extend to the grounds from reopening an award in Article 51." ${ }^{139} \mathrm{El}$ tribunal optó por aplicar la causa de revisión prevista en el art. 51 del Convenio CIADI, aunque de sus palabras ("at least”) se podría pensar que cabrían otros motivos. En efecto, de esta afirmación parece desprenderse que el art. 51 del Convenio CIADI constituye el umbral mínimo para admitir la reconsideración de una decisión; un umbral que, en función de las circunstancias del caso, podría elevarse por encima incluso de los requisitos establecidos en este precepto.

93. Por su parte, el solicitante (Standard Chartered Bank Ltd. (Hong Kong)) alegó dos causas de reconsideración, a saber: primera, que el tribunal había decidido sin conocer hechos materiales ocultados deliberadamente por la contraparte y que, de haberlos conocido su decisión habría sido distinta; $\mathrm{y}$, segunda, un error de derecho.

135 Tethyan Copper Company Pty Limited c. Pakistán (Caso CIADI No ARB/12/1), Laudo 12 de julio de 2019, párr. 165; Standard Chartered Bank (Hong Kong) Limited c. Tanzania Electric Supply Company Limited (Caso CIADI No ARB/10/20), Decisión sobre anulación de 22 de agosto de 2018, párr. 173; Burlington Resources, Inc. c. Ecuador (Caso CIADI N ${ }^{\circ}$ ARB/08/5), Decisión sobre Reconsideración y Laudo de 7 de febrero de 2017, párr. 108; Standard Chartered Bank (Hong Kong) Limited c. Tanzania Electric Supply Company Limited (Caso CIADI No ARB/10/20), Laudo de 12 de septiembre de 2016, párr. 322; por último, menos reciente, Perenco Ecuador Ltd. c. Ecuador y Petroecuador (Caso CIADI N ${ }^{\circ}$ ARB/08/6), Decisión sobre Reconsideración de 10 de abril de 2015, párr. 6.

136 Standard Chartered Bank (Hong Kong) Limited c. Tanzania Electric Supply Company Limited (Caso CIADI N ${ }^{\circ}$ ARB/10/20), Laudo de 12 de septiembre de 2016, párr. 322; y Burlington Resources, Inc. c. Ecuador (Caso CIADI N ${ }^{\circ}$ ARB/08/5), Decisión sobre Reconsideración y Laudo de 7 de febrero de 2017, párr. 96.

137 Standard Chartered Bank (Hong Kong) Limited c. Tanzania Electric Supply Company Limited (Caso CIADI N ${ }^{\circ}$ ARB/10/20), Laudo de 12 de septiembre de 2016, párr. 322; y Burlington Resources, Inc. c. Ecuador (Caso CIADI N ${ }^{\circ}$ ARB/08/5), Decisión sobre Reconsideración y Laudo de 7 de febrero de 2017, párr. 94. Conviene exponer literalmente las palabras del tribunal en el primer caso, reproducidas en el segundo: "In exercising the power to reopen a decision, a tribunal should be guided by, although not bound by, the limitations on reopening that apply to awards."

${ }_{138}$ Standard Chartered Bank (Hong Kong) Limited c. Tanzania Electric Supply Company Limited (Caso CIADI N ${ }^{\circ}$ ARB/10/20), Laudo de 12 de septiembre de 2016, párr. 322; y Burlington Resources, Inc. c. Ecuador (Caso CIADI N ARB/08/5), Decisión sobre Reconsideración y Laudo de 7 de febrero de 2017, párr. 96.

139 Standard Chartered Bank (Hong Kong) Limited c. Tanzania Electric Supply Company Limited (Caso CIADI N ${ }^{\circ}$ $\mathrm{ARB} / 10 / 20)$, Laudo de 12 de septiembre de 2016, párr. 322. [La cursiva es nuestra] 
94. Como el tribunal admitió la primera causa, no entró a valorar si el error de derecho podría justificar la reapertura de la decisión anterior, por lo que queda la duda de si se hubiera admitido el error de derecho como causa de reconsideración. Este caso, además, nos ofrece el primer "precedente" en el que se ha admitido una solicitud de "revisión" en el sistema el CIADI, si bien es cierto que de manera indirecta a través de una solicitud de reconsideración. ${ }^{140}$

95. En segundo lugar, en Burlington Resources, Inc. c. Ecuador el tribunal abordó su facultad de reconsiderar la Decisión sobre responsabilidad dictada con anterioridad, siguiendo la misma práctica, es decir, aplicando por analogía el art. 51 del Convenio CIADI. No obstante, el tribunal expresó su acuerdo con la decisión en $S C B$ c. TANESCO al admitir que para el ejercicio de la facultad de reconsideración debía guiarse por las limitaciones aplicables a los laudos, pero sin estar sujeto a ellas. Estas limitaciones, a juicio del tribunal, incluían la prohibición de apelación (art. 53 del Convenio CIADI), el descubrimiento de un hecho nuevo (art. 51 del Convenio CIADI) y, posiblemente, las causales de anulación (art. 52 del Convenio CIADI). ${ }^{141}$ Una vez más, el término "posiblemente" genera dudas, aunque finalmente el tribunal acabó descartando la posibilidad de aplicar por analogía las causales de anulación. Debe considerarse que la facultad de anular los laudos corresponde a un tribunal distinto al que emite el laudo, por lo que proceder a reconsiderar una decisión sobre la base de estas causales por el mismo tribunal que la adoptó "sería desconocer la organización de facultades"142 prevista en el Convenio CIADI.

96. Por su parte, Ecuador alegó dos causas de reconsideración que fueron: primera, el tribunal cometió un error de derecho; y, segunda, el tribunal fue engañado por Burlington y llegó a su conclusión sobre la base de hechos incompletos. ${ }^{143}$ En cuanto a la primera causa, a la luz de los argumentos aportados por Ecuador para apoyarla, el tribunal la rechazó, ya que, por un lado, entendió que la petición de Ecuador suponía una apelación prohibida por el art. 53 del Convenio CIADI ${ }^{144} \mathrm{y}$, por otro, aportaba un argumento que, por caer en el ámbito de la anulación, resultaba improcedente. ${ }^{145}$ Respecto a la segunda causa, el tribunal entendió que entraba en el alcance de la revisión prevista en el art. 51 del Convenio CIADI, pero finalmente inadmitió la solicitud por no cumplir con todas las condiciones que establece el citado precepto. Conviene destacar que las partes estuvieron de acuerdo en que se podía aplicar la revisión por analogía, aunque Ecuador pretendía que las condiciones de la revisión no se aplicaran como tales a la decisión previa. En concreto, defendió que el plazo fijado en el art. 51.2 del Convenio CIADI no era aplicable, ya que este plazo "se estipuló para evitar revisiones indefinidas luego del dictado de un laudo" y el proceso arbitral aún estaba en curso. ${ }^{146}$ El tribunal rechazó este planteamiento pues el mantenimiento de las condiciones fijadas para la revisión permitía mantener un equilibrio entre los intereses de seguridad jurídica y eficacia procesal y, en particular, el sometimiento a un plazo "alienta el buen comportamiento" del solicitante. ${ }^{147}$ Este razonamiento nos permite identificar la importancia del principio de buena fe también en materia de recursos.

97. No obstante, el comité ad hoc que conoció de la solicitud de anulación planteada por TANES$C O$ contra la Decisión sobre reconsideración, entre otros motivos, dio a entender que la aplicación por analogía del art. 51 del Convenio CIADI no implicaba una aplicación estricta de las condiciones de la revisión:

\footnotetext{
${ }^{140}$ Ninguna solicitud de revisión planteada hasta la fecha conforme al art. 51 del Convenio CIADI ha sido admitida por los órganos arbitrales del CIADI.

${ }^{141}$ Burlington Resources, Inc. c. Ecuador (Caso CIADI No ARB/08/5), Decisión sobre Reconsideración y Laudo de 7 de febrero de 2017, párr. 94.

142 Ibid., párrs. 107-108.

143 Ibid., párrs. 49 y 80.

144 Ibid., párr. 111: "En la medida en que Ecuador afirma que la interpretación por parte del Tribunal del Artículo 74 de la LH y la decisión de prescindir del análisis de si Burlington también podía invocar la exceptio non adimpleti contractus constituyen errores de derecho, el Tribunal coincide con Burlington en que estas presentaciones suponen una apelación. Tal como se analizara supra, las apelaciones son inadmisibles en virtud del Artículo 53 del Convenio CIADI."

145 Ibid. párrs. 113-115.

146 Ibid. párrs. 102-103.

147 Ibid., párr. 104.
} 
"The Committee disagrees. As mentioned above in paragraph 161, the Tribunal did not "apply" Article 51 of the ICSID Convention but simply turned to it seeking guidance on the nature of a discovery that would justify reconsideration of the Decision on Jurisdiction. In the Committee's view, this reliance on Article 51 of the ICSID Convention by analogy did not require the Tribunal to follow that provision to the letter. The Tribunal's reliance on Article 51 of the ICSID Convention was inspired by its desire to make sure that the circumstances before it reached the threshold required to justify the exceptional remedy of reopening an interlocutory decision - which it did."148

98. Este pronunciamiento genera ciertas dudas sobre la "aplicación flexible" de la revisión del art. 51 del Convenio CIADI, puesto que las condiciones para que sea admitida son acumulativas. Se trata de un procedimiento de carácter excepcional y, por consiguiente, aplicar estas condiciones de manera menos rigurosa por tratarse de una decisión preliminar y no un laudo podría poner en riesgo la seguridad jurídica.

99. Por último, en el caso más reciente, Tethyan Cooper c. Pakistán, el órgano arbitral ha confirmado la potestad de reconsiderar y de aplicar el art. 51 del Convenio CIADI por analogía, valorando si los hechos nuevos invocados por Pakistán hubieran sido decisivos. Pakistán alegó haber descubierto dos tipos de errores en los informes de los expertos presentados por la empresa demandante que habrían conducido al tribunal a alcanzar una conclusión errónea en cuanto a la responsabilidad de Pakistán por incumplir el APPRI celebrado entre Australia y Pakistán, al no conceder la licencia de minería a la empresa Tethyan Copper Company Pakistan (Private) Limited. ${ }^{149}$ El tribunal concluyó que estos errores no afectaban a la declaración de responsabilidad de Pakistán. No obstante, señaló que las partes no habían presentado opiniones de expertos independientes en la fase de jurisdicción y responsabilidad; por lo tanto, en la fase de cuantificación de daños el tribunal se pronunciaría sobre las alegaciones del demandado, en la medida en que fuera preciso para valorar los daños causados a la empresa. ${ }^{150}$ Conviene también destacar que el tribunal empleó la misma fórmula que en los casos anteriores, indicando que podía reconsiderar su Decisión sobre jurisdicción y responsabilidad guiándose ("taking guidance") por los requisitos del art. 51 del Convenio CIADI. ${ }^{151}$

100. Por otra parte, en Perenco c. Ecuador, el tribunal no admitió la facultad de reconsiderar, pero su decisión se presenta con cierta ambigüedad. En primer lugar, Ecuador alegó tres motivos que encajan con tres causales de anulación de un laudo (art. 52 del Convenio CIADI), a saber: la violación de normas fundamentales del procedimiento; la extralimitación manifiesta de las facultades del tribunal; y la falta de exposición de los motivos en que se basaba la decisión. Pero, además, Ecuador defendía una facultad amplia del tribunal para reabrir la Decisión sobre jurisdicción y responsabilidad que cuestionaba, es decir, ya fuera sobre alguna de estas causales de anulación o por medio de la causal de revisión o "en cualquier otro caso donde resulte necesario a los fines de hacer justicia", ${ }^{152}$ invocando así todas las acciones posteriores al laudo que la normativa del CIADI prevé.

101. El tribunal resolvió este caso teniendo en cuenta la decisión dictada en ConocoPhillips y otros c. Venezuela y la opinión disidente que la acompañaba. Así, analizó todas las disposiciones del Convenio del CIADI y las Reglas de Arbitraje invocadas por Ecuador, con especial atención en el art.

${ }_{148}$ Standard Chartered Bank (Hong Kong) Limited c. Tanzania Electric Supply Company Limited (Caso CIADI N ${ }^{\circ}$ ARB/10/20), Decisión sobre anulación de 22 de agosto de 2018, párr. 164 y 325.

149 Tethyan Copper Company Pty Limited c. Pakistán (Caso CIADI No ARB/12/1), Laudo 12 de julio de 2019, párr. 166. Ver la Decisión sobre Jurisdicción y Responsabilidad de 10 de noviembre de 2017, párr. 1373.

${ }^{150}$ Tethyan Copper Company Pty Limited c. Pakistán (Caso CIADI No ARB/12/1), Laudo 12 de julio de 2019, párrs. 170171 y $173-174$

${ }^{151}$ Ibid., párr. 165: "In its Decision on Respondent's Reconsideration Request, the Tribunal found that it had the power to reconsider the Decision on Jurisdiction and Liability within a certain scope and limits, in particular taking guidance from the requirements of Article 51 of the ICSID Convention. On that basis, the decisive question for the Tribunal to determine was whether the allegedly newly discovered facts presented by Respondent were "of such a nature as decisively to affect the preaward decision."

${ }^{152}$ Perenco Ecuador Ltd. c. Ecuador y Petroecuador (Caso CIADI No ARB/08/6), Decisión sobre Reconsideración de 10 de abril de 2015, párr. 9 . 
52 (recurso de anulación) a la luz de las causas alegadas por Ecuador. El órgano arbitral concluyó: "El Artículo 52 del Convenio no otorga al Tribunal la facultad de reabrir, modificar y/o dejar sin efecto una decisión previa al dictado del laudo." ${ }^{53} \mathrm{El}$ tribunal destacó que, de todos los procedimientos posteriores al laudo que prevé la normativa del CIADI, el único que permitía una revisión del laudo era el art. 51 del Convenio CIADI, siempre sujeto a la causal expresamente prevista en ese artículo, ${ }^{154}$ pero la solicitud de Ecuador no encajaba en este supuesto. ${ }^{155}$

102. Conviene subrayar que, aunque el órgano arbitral consideró que no tenía la facultad de reconsiderar una decisión previa al laudo, examinó los argumentos de Ecuador "exclusivamente a fines ilustrativos y sin perjuicio de su decisión de que no tiene la facultad de reabrir y reconsiderar sus decisiones en la forma en que Ecuador lo solicita."156

103. En definitiva, en todos estos casos los tribunales arbitrales parecen aceptar la causa de revisión prevista en el art. 51 del Convenio CIADI, es decir, el descubrimiento de un hecho nuevo de influencia decisiva, como justa causa para proceder a la revisión de una decisión preliminar. Esta causa es mucho más limitada que aquellas que disponían las comisiones mixtas y órganos arbitrales en la práctica arbitral internacional clásica. ${ }^{157}$

104. La aplicación por analogía de esta causal de revisión a decisiones anteriores al laudo resulta llamativa, especialmente porque la base jurídica por la que el tribunal se atribuye esta competencia sigue sin estar clara. En Burlington Resources, Inc. c. Ecuador, el tribunal esgrimió como uno de los argumentos a favor de su aplicación que la revisión se sustancia ante el mismo tribunal que dictó el laudo siempre que sea posible. ${ }^{158}$ Esta es una razón práctica que juega en favor de la aplicación de este mecanismo a las decisiones preliminares. Asimismo, la revisión está prevista en la mayoría de normas estatutarias o reglamentarias de los tribunales internacionales. ${ }^{159}$ Incluso se ha llegado a reconocer esta causa de revisión por la Corte Interamericana de Derechos Humanos sin estar prevista la revisión en su normativa. ${ }^{160}$ Además, su contenido básico se encuentra reflejado en la Regla 38.2 de las Reglas de Arbitraje del CIADI como causa que justifica la reapertura del procedimiento antes de que se dicte el laudo. Por consiguiente, la práctica evidencia un acuerdo general (consensus generalis) favorable a reconocer el descubrimiento de un hecho de influencia decisiva como motivo de índole suficiente para modificar una decisión definitiva.

153 Ibid., párr. 97.

154 Ibid., párrs. 41 y 51.

155 Ibid., párr. 50.

${ }^{156}$ Ibid., párr. 97. Interesa destacar que del contenido de la Decisión el tribunal parece no descartar que pueda haber circunstancias que justifiquen en algún caso la reconsideración del tribunal, así en el párr. 6, señala: "En los párrafos 3(c) y (d) de la Resolución Procesal Núm. 11, el Tribunal señaló que "sólo bajo circunstancias excepcionales podría el Tribunal reconsiderar una decisión previa motivada" y, por tanto, le indicó al Ecuador que orientara su Solicitud a establecer "la existencia de dichas circunstancias excepcionales que justificaran la reconsideración" de su Decisión. (...)" Indicamos que no hemos podido consultar la Resolución Procesal N ${ }^{0} 11$, pues no se ha hecho pública; por ello, nos remitimos a este párrafo de la Decisión sobre Reconsideración en el que se alude a la misma.

157 Ver supra, notas 22-23.

158 Burlington Resources, Inc. c. Ecuador (Caso CIADI No ARB/08/5), Decisión sobre Reconsideración y Laudo de 7 de febrero de 2017, párrs. 98 y 108.

159 Art. 61 del Estatuto de la CIJ; art. 44 del Estatuto del Tribunal de Justicia de la Unión Europea, de 1 de julio de 2013 ; art. 127 del Reglamento de procedimiento del Tribunal Internacional de Derecho del Mar, ITLOS/8, 17 de marzo de 2009; Regla 80 del Reglamento del Tribunal Europeo de Derechos Humanos, versión de 1 de agosto de 2018 ; art. 24 del Estatuto del Mecanismo Residual Internacional para los Tribunales Penales Internacionales, aprobado por Resolución del Consejo de Seguridad 1966 (2010), de 22 de diciembre de 2010; art. 55 de la Convención para la resolución pacífica de controversias internacionales de 1899; o art. 83 de la Convención para la resolución pacífica de controversias internacionales de 1907 . El propio órgano arbitral en Burlington Resources, c. Ecuador hizo referencia a la aceptación general de la causa de revisión en otras jurisdicciones internacionales como la CIJ o el Tribunal de Reclamaciones Irán-Estados Unidos: ver Burlington Resources, Inc. c. Ecuador (Caso CIADI No ARB/08/5), Decisión sobre Reconsideración y Laudo de 7 de febrero de 2017, párrs. 100.

${ }^{160}$ Corte IDH. Caso Genie Lacayo vs. Nicaragua. Solicitud de Revisión de la Sentencia de Fondo, Reparaciones y Costas. Resolución de la Corte de 13 de septiembre de 1997. Serie C No. 45, párr. 6. 
105. En suma, existe una opinión mayoritaria entre los órganos arbitrales que han lidiado con solicitudes de reconsideración de que poseen esta facultad de manera limitada, admitiendo por el momento la causa prevista en el art. 51 del Convenio CIADI para la revisión del laudo, a saber, el descubrimiento de un hecho nuevo de influencia decisiva.

\section{La reconsideración: ¿una apelación de facto?}

106. El hecho de que la reconsideración de una decisión preliminar no se encuentre prevista expresamente en la normativa procesal puede dar lugar a diferentes interpretaciones por parte de los tribunales arbitrales del CIADI, tanto respecto a la existencia misma de una facultad de reconsideración, como a las causas que pueden motivar esta acción.

107. El art. 53 del Convenio CIADI prohíbe la apelación del laudo y cualquier otro recurso, salvo los mecanismos previstos en la normativa CIADI, como ya se expuso. De hecho, en el seno del CIADI se exploró la posibilidad de introducir un órgano de apelación único o centralizado, pero finalmente esta propuesta se consideró prematura y no prosperó. ${ }^{161}$ Por ello, parece clara la intención de los Estados partes del Convenio CIADI de excluir la posibilidad de apelación del laudo.

108. Sin embargo, actualmente en el Grupo de Trabajo III de la CNUDMI se debate sobre una posible reforma del sistema de solución de controversias entre inversores y Estados. En este marco institucional algunos Estados y también la Unión Europea ${ }^{162}$ han abogado, entre otras propuestas, por la creación de un tribunal multilateral de inversiones de carácter permanente y un mecanismo de apelación único. ${ }^{163} \mathrm{El}$ objetivo de los mismos sería favorecer una interpretación unitaria de las normas aplicables en materia de inversiones extranjeras que contribuyera a garantizar la coherencia, consistencia y previsibilidad de la práctica arbitral, así como corregir, naturalmente, los posibles errores cometidos por los árbitros.

109. Debe tenerse en cuenta que, en un sistema de justicia arbitral descentralizado donde los tribunales se constituyen ad hoc, es natural que su composición varíe de un caso a otro, aunque los miembros sean elegidos de la lista de árbitros que ofrece la institución, en este caso, el CIADI. ${ }^{164}$ Este fenómeno acentúa el riesgo de que se produzca una divergencia de opiniones derivada de la aplicación de criterios interpretativos distintos o sencillamente de enfoques distintos de los árbitros según su formación privatista o publicista. En particular, un tribunal multilateral permanente de inversiones y un órgano de apelación único podrían minimizar el riesgo de interpretaciones discordantes y contribuir a crear un verdadero cuerpo jurisprudencial en este sector normativo. En todo caso, el hecho de que se esté valorando la creación de un órgano multilateral de apelación, cualquiera que sea la forma que finalmente

${ }^{161}$ Véase la propuesta de introducir un órgano de apelación en el CIADI en ICSID Secretariat, Discussion Paper, Possible Improvements of the Framework for ICSID Arbitration, de 22 de octubre de 2004, p. 14 y ss. Finalmente, se desistió en esta reforma: ver ICSID Secretariat, Working Paper, Suggested Changes to the ICSID Rules and Regulations, de 12 de mayo de 2005, párr. 4.

${ }^{162}$ Desde 2015 la Comisión Europea está impulsando la creación de un tribunal multilateral de inversiones que cuente con una primera instancia y una segunda instancia de apelación. Algunos tratados recientes de libre comercio e inversión firmados por la UE con terceros países ya contienen cláusulas que hacen referencia a este tribunal multilateral permanente de inversiones y a un órgano de apelación: ver inter alia, art. 8.29 del Acuerdo entre la UE y Canadá (CETA), de 30 de octubre de 2016, en vigor provisionalmente desde el 21 de septiembre de 2017; o el art. 3.41 del Acuerdo entre la UE y Vietnam, de 30 de junio de 2019. Véase también el Documento presentado por la Unión Europea y sus Estados miembros al Grupo de Trabajo III de la CNUDMI, de 18 de enero de 2019, y otros documentos relevantes sobre la propuesta de constituir un tribunal multilateral de inversiones en la web de la Comisión Europea http://trade.ec.europa.eu/doclib/press/index.cfm?id=1608

${ }_{163}$ A/CN.9/1004/Add.1, de 28 de enero de 2020; A/CN.9/WG.III/WP.185, de 29 de noviembre de 2019; y A/CN.9/WG.III/ WP.150, de 28 de agosto de 2018. Sobre estas reformas: ver E. Fernández MASIÁ y M. SALVAdORI, "Lo que se está discutiendo en la CNUDMI: Evolución o revolución en el sistema de solución de controversias inversor-estado", Cuadernos de Derecho Transnacional, vol. 12, $\mathrm{n}^{\circ}$ 1, 2020, pp. 203-218.

${ }^{164}$ A medida que ha aumentado el número de Estados partes en el Convenio CIADI, ha aumentado significativamente el número de árbitros que se encuentran inscritos en la lista de árbitros y conciliadores: ver https://icsid.worldbank.org/sp/Pages/ arbitrators/CVSearch.aspx 
adopte, pone de manifiesto que quizás el sistema de recursos actual previsto para los laudos arbitrales en materia de inversiones no sea satisfactorio.

110. Sin embargo, todavía quedan muchas cuestiones abiertas que deben ser afrontadas para poder alcanzar un consenso sobre la introducción de este órgano de apelación, entre otras: ¿cuáles serían los motivos de apelación?; ¿podría solicitarse la apelación solo por errores de derecho o también por errores de hecho?; ¿sería admisible cualquier error o solo aquellos graves o manifiestos?; o ¿cuáles serían las consecuencias jurídicas de la apelación y cómo se gestionaría una decisión que la admitiera? ${ }^{165}$

111. Las causas que motivan un recurso deben estar claramente definidas con el objetivo de evitar que se haga un uso indebido del mismo. También en materia de recursos las partes enfrentadas deben mantener una conducta conforme con el principio general de buena fe y no intentar desvirtuar el sistema de justicia mediante subterfugios. ${ }^{166}$

112. Por ello, una de las cuestiones principales a dilucidar por los órganos arbitrales en los casos de reconsideración estudiados ha sido determinar los motivos que pueden justificar tal acción. A nuestro juicio, cualquier interpretación que conduzca a confundir la reconsideración con una apelación o una anulación sería contraria a la letra del Convenio CIADI y a la intención de sus redactores.

113. Se ha expuesto cómo en $S C B$ c. TANESCO el tribunal se pronunció sobre la primera causa relativa a la ocultación deliberada de una información esencial para la solución de la controversia y procedió a la reconsideración de su decisión, por lo que decidió no entrar en la segunda causa basada en un error de derecho, sin especificar si sería posible o no proceder a reconsiderar la decisión por esta causa. Un error de derecho es una causa general que motiva una apelación, por lo que la solicitante de reconsideración en este litigio ¿no estaría entonces formulando una apelación de facto?

114. En el marco del CIADI se presentan importantes dificultades técnicas que impiden la introducción de un mecanismo de apelación. El reto más evidente es la prohibición de apelación prevista en el art. 53 del Convenio CIADI. Sería necesaria, por tanto, una enmienda de dicho instrumento internacional; un procedimiento que requeriría la unanimidad de los Estados partes (art. 66 del Convenio CIADI), lo que es especialmente difícil de lograr en el actual contexto internacional. Por eso, resulta muy conveniente valorar otras alternativas a la apelación que permitan potenciar la coherencia, consistencia y corrección de las decisiones arbitrales. ${ }^{167}$

115. En nuestra opinión, la reconsideración se podría estar empleando en el marco del CIADI como una alternativa, ante la ausencia de un mecanismo de apelación. Las dificultades técnicas que impiden introducir una apelación en este marco institucional se verían salvadas por medio de la reconsideración si se permitiera que esta se planteara por causa de un error de hecho o de derecho; es decir, aunque de iure no existiera un recurso de apelación, se estaría produciendo de facto por medio de una "reconsideración". Debe tenerse en cuenta que no solo se ha planteado la reconsideración de decisiones preliminares sobre cuestiones de competencia y jurisdicción, sino también sobre responsabilidad, por lo

\footnotetext{
165 A/CN.9/1004/Add.1, de 28 de enero de 2020, párrs. 25-30.

${ }^{166}$ Sobre el uso indebido de los recursos: ver L. Aragonés Molina, "El riesgo de apelación encubierta en el arbitraje de inversión ante el Ciadi”, en A. Guerrero Ortega, G. Ros Magán, P. Ruiz Benito, F. Pascual-Vives, C. Tejedor Martínez y V. Tabernero Magro, (eds.), Séptimas jornadas de jóvenes investigadores de la Universidad de Alcalá, Servicio de Publicaciones de la Universidad de Alcalá, Alcalá de Henares 2019, pp. 81-90.

${ }^{167}$ Sobre los problemas y las posibles alternativas en torno a la introducción de un mecanismo de apelación en el arbitraje de inversión ante el CIADI. Ver, inter alia, C.J. TAms, loc. cit., 49 pp.; Ch.H. Schreuer y A. De La Brena, "Does ISDS Need an Appeals Mechanism?", Transnational Dispute Management, $\mathrm{n}^{\circ}$ 2, 2020, 8 pp. Asimismo, se menciona la dificultad de introducir un mecanismo de apelación en el CIADI y se mencionan algunos mecanismos alternativos en el documento de la Secretaría de la CNUDMI: ver A/CN.9/WG.III/WP.185, de 29 de noviembre de 2019, párrs. 38 y 49 (respecto a este último párrafo, véanse las notas al pie 53-55); y A/CN.9/1004/Add.1, de 28 de enero de 2020, párrs. 78-79.
} 
que la reconsideración se presentaría como una alternativa factible frente a la ausencia de una apelación para conseguir una modificación sustantiva de una decisión que, naturalmente, influiría en el laudo definitivo al incorporarse al mismo. Técnicamente no se estaría vulnerando el art. 53 del Convenio CIADI, pues la reconsideración afecta a una decisión preliminar, no al laudo. Además, al corregirse el error en un procedimiento todavía abierto, las partes ahorrarían en costes y tiempo en comparación con la opción de plantear un recurso de apelación contra el laudo.

116. Conviene destacar que, en los debates sustanciados en la CNUDMI, algunos Estados han propuesto que la futura apelación se pueda plantear contra decisiones de jurisdicción en un procedimiento todavía en curso. ${ }^{168}$ Asimismo, en la propuesta que se debatió en el seno del CIADI para la introducción de un mecanismo de apelación también se expuso que, ante la aproximación particular que se mantiene en el CIADI acerca de los conceptos de decisión preliminar y laudo, sería necesario que, para evitar divergencias entre casos del CIADI y casos ajenos al CIADI, las reglas procesales del órgano de apelación establecieran claramente si sería posible o no impugnar los laudos parciales y las decisiones preliminares. ${ }^{169}$ A nuestro juicio, esta indicación en la propuesta debatida en 2004 pone de relieve que actualmente la estructura del CIADI no prevé la impugnación de decisiones preliminares y que, en efecto, sería necesario, para evitar interpretaciones divergentes entre los tribunales, que esta cuestión estuviera claramente prevista en la normativa procesal.

117. Ahora bien, la alternativa de la reconsideración por causa de cualquier error de hecho o de derecho sólo contribuiría, como máximo, a garantizar la corrección del laudo definitivo, pero no evitaría los riesgos de discordancia en la práctica arbitral. También debe tenerse en cuenta que la reconsideración la lleva a cabo el mismo órgano arbitral, al tratarse de un procedimiento en curso, y no un tribunal distinto, como habitualmente sucede con la apelación o la anulación. El recurso ante otro tribunal pretende aportar, precisamente, cierta garantía de corrección de la decisión, al ser sometida a un doble examen por árbitros distintos a los que la dictaron.

118. En cualquier caso, reiteramos que, a nuestro juicio, utilizar esta vía para lograr una modificación sustantiva de una decisión previa al laudo, no sería acorde a la letra del Convenio CIADI en su versión actualmente vigente, por lo que si un órgano arbitral considera que puede ejercer esta facultad, como se ha visto en los casos más recientes, es necesario que limite su utilización a causas específicas y tasadas y, todavía bajo esos parámetros, constituye una solución discutible que conlleva ciertos riesgos.

119. El órgano arbitral en Burlington Resources, Inc. c. Ecuador fue claro al rechazar la primera causa alegada por Ecuador al considerar que se trataba de una apelación prohibida por el art. 53 del Convenio CIADI. Asimismo, en Perenco c. Ecuador y en Burlington Resources, Inc. c. Ecuador se alegaron causales para la reconsideración de la decisión propias de un recurso de anulación (art. 52 del Convenio CIADI) y los órganos arbitrales rechazaron esta posibilidad.

120. En general, se ha admitido la reconsideración por causa del descubrimiento de un hecho nuevo, aplicando por analogía el art. 51 del Convenio CIADI, aunque a veces con cierta ambigüedad, es decir, sin dejar claro si caben otras causas de reconsideración, como podrían ser las causas de anulación, o si cabe una aplicación "flexible" de las condiciones de revisión. Aunque sería conveniente que los órganos arbitrales se pronunciaran con mayor claridad sobre las causas de reconsideración, se observa que su intención es limitar su alcance y no convertirla en una apelación de facto.

121. Por otra parte, también interesa valorar si, en caso de que se creara un mecanismo de apelación, se seguiría solicitando la reconsideración de estas decisiones preliminares. A nuestro juicio, a

\footnotetext{
${ }^{168}$ A/CN.9/1004/Add.1, de 28 de enero de 2020, párr. 33.

${ }^{169}$ ICSID Secretariat, Discussion Paper, Possible Improvements of the Framework for ICSID Arbitration, de 22 de octubre de 2004, Annex, párr. 8.
} 
la luz de las causas alegadas en los casos estudiados, consideramos que lo más probable es que no se solicitara la reconsideración, sino que los interesados acudirían a la apelación. ${ }^{170} \mathrm{Si}$ finalmente se creara un órgano de apelación único y permanente, además de favorecer la corrección de las decisiones, este órgano podría dotar de una mayor coherencia y consistencia a los laudos definitivos; objetivo que no se logra actualmente por medio de la reconsideración. El inconveniente, no obstante, sería el mayor tiempo que requeriría el procedimiento y el coste que supondría para los litigantes, cuestiones todas ellas que deberían tenerse en cuenta a la hora de decidir los plazos para interponer el recurso de apelación o el plazo en que el órgano de apelación debe resolver, así como la adopción de medidas que impidieran el planteamiento de recursos infundados con el propósito de retrasar la ejecución del laudo, por ejemplo, mediante la imposición de costas a la parte recurrente si se aprecia que ha obrado de mala fe.

\section{Conclusiones}

122. En el seno del CIADI se ha solicitado en varias ocasiones la reconsideración de las decisiones preliminares que resuelven tanto excepciones a la jurisdicción, como cuestiones de responsabilidad. El eje central de la discusión mantenida en todos estos litigios ha sido el posible efecto de cosa juzgada de las decisiones previas al laudo. Los órganos arbitrales se han mostrado divididos en torno a esta cuestión. No obstante, es mayoritaria la opinión de que las decisiones preliminares no poseen efecto de cosa juzgada hasta que se incorporan al laudo, respondiendo así a la consideración de la normativa procesal del CIADI como lex specialis y, por ende, a la propia estructura de este sistema. Lo anterior no quiere decir que estas decisiones puedan reabrirse en cualquier momento, a discreción de las partes. Esta circunstancia sería contraria a la seguridad jurídica y prolongaría los procedimientos indefinidamente en detrimento de la eficacia procesal.

123. Al hilo del debate sobre el efecto de cosa juzgada, surge la cuestión de la posible reconsideración de estas decisiones, es decir, si es posible admitir una suerte de recurso que no está previsto expresamente en la normativa del CIADI. Por un lado, los tribunales que han concluido que las decisiones preliminares no poseen efecto de cosa juzgada entienden que pueden reexaminarlas en el curso del procedimiento, si bien bajo condiciones limitadas. Por otro, los órganos arbitrales que han abogado por el efecto de cosa juzgada admiten que estas decisiones no pueden ser reabiertas hasta que se incorporen al laudo y se interponga alguno de los recursos que la normativa CIADI prevé contra los laudos.

124. Ambas posiciones revisten ventajas e inconvenientes. Por un lado, la solución adoptada por los órganos arbitrales del CIADI que confirma la posibilidad de reconsiderar una decisión preliminar permite subsanar un error antes de que se pronuncie un laudo definitivo que se dictaría sobre unos presupuestos erróneos, favoreciendo así una buena administración de justicia. De lo contrario, posiblemente el error daría lugar al planteamiento de un recurso de revisión o anulación contra el laudo en los términos previstos en la normativa CIADI, si se dieran las condiciones para ello, lo que supondría una prolongación del proceso y un mayor coste económico para las partes o, en el peor de los casos, es decir, si no se dieran las condiciones tasadas para el planteamiento de estos recursos y en ausencia de apelación, quedaría confirmada una decisión injusta. Por lo tanto, la reconsideración puede entenderse como un recurso que favorece la buena administración de justicia, tanto desde la celeridad y eficacia con que los jueces y árbitros deben resolver las causes traídas ante ellos, como desde el punto de vista de la garantía de la corrección de la decisión y, en definitiva, de la justicia del laudo definitivo que incorporará todas las decisiones anteriores.

125. Por otro lado, no hay que olvidar que la reconsideración es un recurso que no está previsto expresamente en la normativa CIADI, por lo que su base jurídica es controvertida. Los órganos jurisdiccio-

\footnotetext{
${ }^{170}$ Interesa señalar que en la propuesta que se debatió en el seno del CIADI para la introducción de un mecanismo de apelación se establecía que se pudiera apelar el laudo por un claro error de derecho, un error de hecho grave o por alguna de las causas del art. 52 del Convenio CIADI. ICSID Secretariat, Discussion Paper, Possible Improvements of the Framework for ICSID Arbitration, de 22 de octubre de 2004, Annex, párr. 7.
} 
nales precisan de ciertas facultades inherentes para garantizar el correcto desarrollo del procedimiento. Las normas procesales no pueden prever con total exhaustividad las situaciones que pueden surgir en la práctica, por lo que es razonable que los jueces y árbitros cuenten con cierto margen de discrecionalidad para resolver en función de las circunstancias del caso. El art. 44 del Convenio CIADI prevé expresamente la facultad de los tribunales arbitrales para colmar lagunas procesales, pero cabe preguntarse si puede considerarse la reconsideración una laguna procesal subsanable mediante un poder inherente del órgano arbitral.

126. Ciertamente, los límites de los poderes inherentes son difíciles de establecer. Conforme han señalado algunos órganos arbitrales del CIADI, estos límites estarían en la norma constitutiva de estos tribunales y en las normas de procedimiento aplicables, conforme a la intención de sus redactores. Así, la normativa del CIADI prohíbe la apelación y únicamente es posible plantear acciones de impugnación contra el laudo en los términos expresamente previstos por ella. A nuestro juicio, la intención de los redactores del Convenio CIADI era clara en cuanto a la exclusión de la apelación y a la limitación de las posibilidades de impugnación del laudo. Consideramos, por tanto, que una facultad de reconsideración de las decisiones sobre el fondo no encuentra cabida en los poderes inherentes que atribuye el art. 44 del Convenio CIADI a los órganos arbitrales para colmar lagunas procesales.

127. Ahora bien, en nuestra opinión, un doble fundamento puede sustentar este modo de proceder seguido por algunos tribunales arbitrales del CIADI en los casos más recientes. Primero, el carácter especializado del CIADI en cuanto a la diferenciación entre "decisión" y "laudo", en la medida en que las decisiones preliminares no gozan de efecto de cosa juzgada y, por ello, pueden modificarse a lo largo del procedimiento. Y, segundo, en determinados principios generales del derecho, como los principios de economía procesal y buena administración de justicia, ya que esperar a la emisión del laudo definitivo para interponer un recurso posterior que pueda corregir el error cometido, iría en detrimento de la eficacia procesal, además de prolongar la controversia entre las partes, con los perjuicios que ello conlleva no solo para los litigantes, sino para la confianza en este sistema de arreglo de controversias.

128. Como han afirmado los órganos arbitrales que se han pronunciado a favor de la reconsideración, esto no significa que las decisiones preliminares no sean obligatorias o sean susceptibles de modificación en todos los casos. Si se opta por la reconsideración, es esencial establecer unas condiciones claras para proceder a modificar una decisión de esta índole con el objetivo de evitar abusos del proceso, por ejemplo, utilizar la reconsideración como táctica dilatoria o introducir un nuevo recurso en la normativa del CIADI por la vía de facto y en contra de la letra del Convenio y de la intención de sus redactores. Hasta el momento, estas condiciones han sido las previstas para la revisión del laudo conforme al art. 51 del Convenio CIADI, esto es, el descubrimiento de un hecho nuevo de influencia decisiva.

129. La práctica es todavía escasa y la divergencia de opiniones en las decisiones de los árbitros, que no ha sido accidental, sino deliberada, como demuestran las referencias mutuas entre estos órganos arbitrales, así como la ambigüedad en algunos pronunciamientos sobre las causas que motivarían la reconsideración, generan cierta incertidumbre respecto a la posibilidad de plantear este tipo de solicitudes. Es necesario tener en cuenta que los órganos arbitrales creados en el marco del CIADI forman un mecanismo de solución de controversias dotado de una serie de particularidades, entre ellas, la que aquí se ha presentado, que es la diferencia entre "decisión" y "laudo". Las particularidades de un sector pueden influir en la interpretación que los tribunales realicen de la normativa procesal.

130. Por ello, se aprecia un mayor riesgo de fragmentación intrasistémica, es decir, en el arbitraje de inversión institucional del CIADI, que intersistémica, esto es, respecto al DI general. No obstante, el hecho de que la decisión más reciente en Tethyan Cooper c. Pakistán se haya conformado a las decisiones previas en Burlington Resources c. Ecuador, SCB c. TANESCO y el posicionamiento a favor de la decisión del tribunal en $S C B$ c. TANESCO por el comité ad hoc en el procedimiento de anulación incoado en este último caso, indica una tendencia de los órganos arbitrales a consolidar una determinada posición y frenar la discrepancia, lo que sin duda favorece la previsibilidad, coherencia y unidad del subsistema. 